\title{
The Renal Clearable Magnetic Resonance Imaging Contrast Agents: State of the Art and Recent Advances
}

\author{
Xiaodong $\mathrm{Li}^{1}$, Yanhong Sun ${ }^{2}$, Lina Ma ${ }^{2}$, Guifeng Liu ${ }^{1, *}$ and Zhenxin Wang ${ }^{2, *}$ (]) \\ 1 Department of Radiology, China-Japan Union Hospital of Jilin University, Xiantai Street, Changchun 130033, \\ China; xiaodong20@mails.jlu.edu.cn \\ 2 State Key Laboratory of Electroanalytical Chemistry, Changchun Institute of Applied Chemistry, \\ Chinese Academy of Sciences, Changchun 130022, China; yhyan@ciac.ac.cn (Y.S.); malina@ciac.ac.cn (L.M.) \\ * Correspondence: gfliu@jlu.edu.cn (G.L.); wangzx@ciac.ac.cn (Z.W.); Tel.: +86-431-8499-5700 (G.L.); \\ +86-431-8526-2243 (Z.W.)
}

Academic Editor: Igor Serša

Received: 12 October 2020; Accepted: 26 October 2020; Published: 1 November 2020

\begin{abstract}
The advancements of magnetic resonance imaging contrast agents (MRCAs) are continuously driven by the critical needs for early detection and diagnosis of diseases, especially for cancer, because MRCAs improve diagnostic accuracy significantly. Although hydrophilic gadolinium (III) $\left(\mathrm{Gd}^{3+}\right)$ complex-based MRCAs have achieved great success in clinical practice, the $\mathrm{Gd}^{3+}$-complexes have several inherent drawbacks including $\mathrm{Gd}^{3+}$ leakage and short blood circulation time, resulting in the potential long-term toxicity and narrow imaging time window, respectively. Nanotechnology offers the possibility for the development of nontoxic MRCAs with an enhanced sensitivity and advanced functionalities, such as magnetic resonance imaging (MRI)-guided synergistic therapy. Herein, we provide an overview of recent successes in the development of renal clearable MRCAs, especially nanodots (NDs, also known as ultrasmall nanoparticles (NPs)) by unique advantages such as high relaxivity, long blood circulation time, good biosafety, and multiple functionalities. It is hoped that this review can provide relatively comprehensive information on the construction of novel MRCAs with promising clinical translation.
\end{abstract}

Keywords: magnetic resonance imaging contrast agents; renal clearance; nanodots; gadolinium (III)-based composites

\section{Introduction}

Magnetic resonance imaging (MRI) is extensively used as a noninvasive, nonionizing, and radiation-free clinical diagnosis tool for detection and therapeutic response assessment of various diseases including cancer, because it can provide anatomical and functional information of regions-of-interest (ROI) with high spatial resolution through manipulating the resonance of magnetic nucleus (e.g., ${ }^{1} \mathrm{H}$ ) in the body via an external radiofrequency pulse magnetic field [1-7]. Although it is possible to generate high-contrast images of soft tissues for diagnosis by manipulating pulse sequences alone, MRI is able to further highlight the anatomic and pathologic features of ROI through utilized in concert with contrast agents. Magnetic resonance imaging contrast agents (MRCAs) play an extremely important role in modern radiology because the growth of contrast-enhanced MRI has been remarkable since 1988 [3-8]. Up to date, the commercially approved MRCAs and the MRCAs in clinical trial are shown in Table 1. 
Table 1. Typical magnetic resonance imaging contrast agents (MRCAs) clinically approved or in clinical trials.

\begin{tabular}{|c|c|c|c|c|c|}
\hline Trade Name & Generic Name & Chemical Code & MRI Mode & Clinical Trial & Clinically Approved \\
\hline Dotarem/Clariscan & Gadoterate meglumine & Gd-DOTA & $\mathrm{T}_{1}$-weighted & - & Yes \\
\hline ProHance & Gadoteridol & Gd-HPDO3A & $\mathrm{T}_{1}$-weighted & - & Yes \\
\hline Gadovist & Gadobutrol & Gd-DO3A-butrol & $\mathrm{T}_{1}$-weighted & - & Yes \\
\hline Magnevist & $\begin{array}{l}\text { Gadopentetate } \\
\text { dimeglumine }\end{array}$ & Gd-DTPA & $\mathrm{T}_{1}$-weighted & - & Yes \\
\hline Omniscan & Gadodiamide & Gd-DTPA-BMA & $\mathrm{T}_{1}$-weighted & - & Yes \\
\hline Optimark & Gadoversetamide & Gd-DTPA-BMEA & $\mathrm{T}_{1}$-weighted & - & Yes \\
\hline Multihance & $\begin{array}{l}\text { Gadobenate } \\
\text { dimeglumine }\end{array}$ & Gd-BOPTA & $\mathrm{T}_{1}$-weighted & - & Yes \\
\hline Combidex/Sinerem & Ferumoxtran & Dextran coated SPION & $\mathrm{T}_{2}$-weighted & Yes & - \\
\hline Resovist/Cliavist & Ferucarbotran/Ferrixan & Carboxydextran coated SPION & $\mathrm{T}_{2}$-weighted & - & Yes \\
\hline Feridex I.V./Endorem & Ferumoxide & Dextran & $\mathrm{T}_{2}$-weighted & - & Yes \\
\hline Feraheme/Rienso & Ferumoxytol & $\begin{array}{l}\text { Carboxymethyl-dextran coated } \\
\text { SPION }\end{array}$ & $\mathrm{T}_{2}$-weighted & - & Yes \\
\hline Clariscan & Feruglose & PEGylated starch coated SPION & $\mathrm{T}_{2}$-weighted & Yes & - \\
\hline Lumirem/GastroMARK & Ferumoxsil & $\begin{array}{l}\text { Siloxane coated SPION } \\
\text { Sulfonated poly }\end{array}$ & $\mathrm{T}_{2}$-weighted & - & Yes \\
\hline Abdoscan & - & $\begin{array}{l}\text { (styrene-divinylbenzene) } \\
\text { copolymer coated SPION }\end{array}$ & $\mathrm{T}_{2}$-weighted & - & Yes \\
\hline
\end{tabular}

In general, there are two imaging modes of MRI, named as $\mathrm{T}_{1}$ - or $\mathrm{T}_{2}$-weighted MRI, which have been employed to acquire the restored or residual magnetization by adjusting parameters in either the longitudinal direction or the transverse plane, respectively. The $\mathrm{T}_{1}$-weighted $\mathrm{MR}$ image shows bright signal contrast (recovered magnetization), while the $\mathrm{T}_{2}$-weighted MR image shows dark signal contrast (residual magnetization). The $\mathrm{T}_{1^{-}}$or $\mathrm{T}_{2}$-weighted MRI can be performed in one machine by simply adjusting the acquisition sequences during the MRI process. Consequently, the MRCAs are divided into two categories based on their dominant functions in $\mathrm{T}_{1}$ - or $\mathrm{T}_{2}$-weighted MRI. Paramagnetic metal nanomaterials/complexes are usually designated as $\mathrm{T}_{1}$-weighted MRCAs, which cause bright contrast in $\mathrm{T}_{1}$-weighted MR images [3,4,8-10]. For example, gadolinium (III) $\left(\mathrm{Gd}^{3+}\right)$ has seven unpaired electrons and a long electron spin relaxation time, which can efficiently promote the longitudinal ${ }^{1} \mathrm{H}$ relaxation. $\mathrm{Gd}^{3+}$-diethylenetriamine penta-acetic acid (Gd-DTPA) was synthesized as the first $\mathrm{T}_{1}$-weighted MRCA and used for contrast-enhanced $\mathrm{T}_{1}$-weighted MRI of intracranial lesions in 1988 [8]. Superparamagnetic nanoparticles (e.g., superparamagnetic iron-oxide nanoparticles (SPIONs)) are normally used as $\mathrm{T}_{2}$-weighted MRCAs, which provide dark contrast in MR images [11-19]. The advantages and disadvantages of $\mathrm{Gd}^{3+}$ - and SPION-based MRCAs have been discussed in the reviews which are published elsewhere [3-19]. In particular, the advent of nephrogenic systemic fibrosis (NSF) and bone/brain deposition has led to increased regulatory scrutiny of the safety of commercial $\mathrm{Gd}^{3+}$ chelates [9]. Figure 1 shows the typical paramagnetic cations including transition metallic cations and lanthanide cations, which are capable of enhancing contrast on MR images. The cations contain unpaired electrons in $3 \mathrm{~d}$ electron orbitals (transition metallic cations) and/or 4 f electron orbitals (lanthanide cations). In addition, several strategies have been proposed for development of $T_{1}-/ T_{2}$-weighted dual-mode MRCAs, because $T_{1}-/ T_{2}$-weighted dual-mode MRI can provide an accurate match of spatial and temporal imaging parameters [12]. Therefore, the accuracy and reliability of disease diagnosis can be clearly improved by synergistically enhancing both $\mathrm{T}_{1}-\mathrm{T}_{2}$-weighted contrast effects.

Because of their unique physiochemical and magnetic properties, magnetic nanoparticles (MNPs) have attracted considerable attention in the construction of MRCAs with high performance during the last two decades (as shown in Figure 2), and they exhibit high potential for clinical applications in MRI-guided therapy. The synthesis, properties, functionalization strategies, and different application potentials of MNPs have been reviewed in detail in the literature published elsewhere [11-19]. For example, the MNPs can be used as excellent MRCAs for sensitive detection of tumors because MNPs can efficiently accumulate in tumor through the leaky vasculature of tumor (also known as the enhanced permeability and retention (EPR) effect). The contrast efficacy and in vivo fate of the MNP-based MRCAs are strongly dependent on their physical and chemical features including shape, size, surface charge, surface coating material, and chemical/colloidal stability. For example, the PEGylated 
MNPs normally have relatively longer blood circulation time and higher colloidal/chemical stability than those of uncoated MNPs [11]. Very recently, the structure-relaxivity relationships of magnetic nanoparticles for MRI have been summarized in detail by Chen et al. [15]. Among all the characteristics of MNP, size plays a particularly important role in the biodistribution and blood circulation half-life of MNP $[15,18,20]$. The long blood circulation half-life of MNP can significantly increase the time window of imaging. However, the nonbiodegradable MNPs with large hydrodynamic size (more than $10 \mathrm{~nm}$ ) exhibit high uptake in the reticuloendothelial system (RES) organs such as lymph nodes, spleen, liver, and lung, which causes slow elimination through hepatobiliary excretion [21]. The phenomenon increases the likelihood of toxicity in vivo [22], and severely hampers translating MNPs into clinical practices because the United States Food and Drug Administration (FDA) requires that any imaging agent (administered into the body) should be completely metabolized/excreted from the body just after their intended medical goals such as image-guided therapy [23]. The conundrum could be sorted out by the development of renal clearable MNPs since renal elimination enables rapidly clear intravenously administered nanoparticles (NPs) from circulation to be excreted from body. Due to the pore size limit of glomerular filtration in the kidney, only the MNPs with small hydrodynamic diameter (less than $10 \mathrm{~nm}$ ) or biodegradable ability are able to balance the long blood circulation half-life time for imaging and efficient renal elimination for biosafety. In addition, although they have similar small hydrodynamic diameters, the negatively charged or neutral NPs are more difficult to be eliminated by the kidney than their positively charged counterparts.

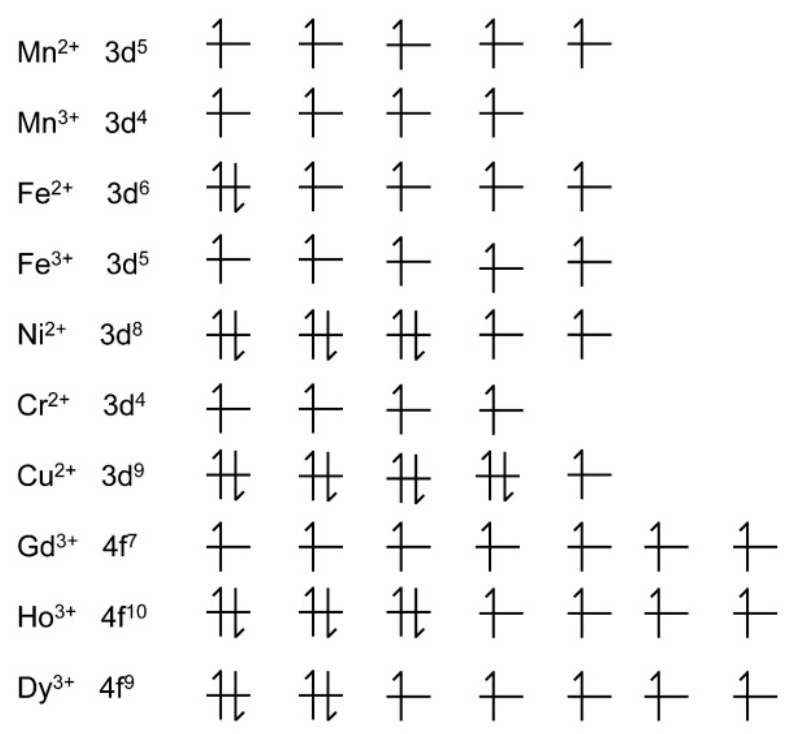

Figure 1. The electron subshell diagrams of typical paramagnetic cations. Generally, the larger number of unpaired electrons leads to stranger magnetic resonance (MR) contrast.

Herein, this review provides the state of the art of renal clearable composites/MNPs-based MRCAs with particular focus on several typical formats, namely $\mathrm{Gd}^{3+}$-complex-based composites and magnetic metal nanodots (MNDs), by using illustrative examples. The MNDs mean MNPs with ultrasmall hydrodynamic size (typically less than $10 \mathrm{~nm}$ in diameter) such as ultrasmall $\mathrm{Gd}_{2} \mathrm{O}_{3}$ NPs, ultrasmall $\mathrm{NaGdF}_{4} \mathrm{NPs}$, ultrasmall $\mathrm{Fe}_{2} \mathrm{O}_{3} / \mathrm{Fe}_{3} \mathrm{O}_{4} \mathrm{NPs}$ and ultrasmall polymetallic oxide NPs. The gathered data clearly demonstrate that renal clearable composites/MNDs offer great advantages in MRI, which shows a great impact on the development of theranostic for various diseases, in particular for cancer diagnosis and treatment. In addition, we also discussed current challenges and gave an outlook on potential opportunities in the renal clearable composites/MNDs-based MRCAs. 


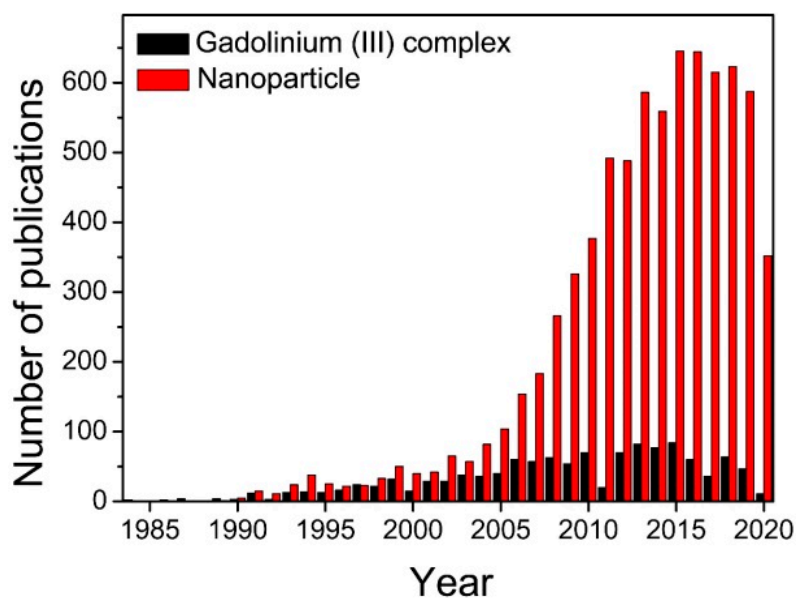

Figure 2. The number of publications searching for "magnetic resonance imaging and contrast agents" plus "gadolinium (III) complex" or "nanoparticle" in the "Web of Science". Development of nanoparticle-based MRCAs has been the hot topic of the area since 2005.

\section{Gadolinium (III)-Complex-Based Composites}

Up to date, all of the MRCAs commercially available in clinic are small molecule $\mathrm{Gd}^{3+}$-complexes, which are used in about $40 \%$ of all MRI examinations (i.e., about 40 million administrations of $\mathrm{Gd}^{3+}$-complex-based MRCA) [24]. However, the small molecule $\mathrm{Gd}^{3+}$-complexes generally have short blood circulation time with a typical elimination half-life of about $1.5 \mathrm{~h}[8,9,25-27]$. The rapid clearance characteristic of small molecule $\mathrm{Gd}^{3+}$-complex makes it difficult to conduct the time-dependent MRI studies. Conjugation of $\mathrm{Gd}^{3+}$-complexes with biodegradable materials (e.g., polymers) and/or renal clearable NDs can not only significantly prolong blood circulation of $\mathrm{Gd}^{3+}$-complexes, but also improve accumulation amount of $\mathrm{Gd}^{3+}$-complexes in solid tumors through an EPR effect [28-52]. Therefore, the $\mathrm{Gd}^{3+}$-complex-based composites enable one to provide an imaging window of a few hours before it is cleared from the body, and additionally enhance the resulting MR signal of a tumor. In particular, biodegradability or small size that ensures the complete clearance of $\mathrm{Gd}^{3+}$-complex-based composites within a relatively short time (i.e., a day) by renal elimination after diagnostic scans.

As early as 2012, Li and coauthors synthesized a poly( $N$-hydroxypropyl-L-glutamine)-DTPA-Gd (PHPG-DTPA-Gd) composite through conjugation of Gd-DTPA on the poly( $N$-hydroxypropylL-glutamine) (PHPG) backbone [34]. The longitudinal relaxivity ( $\left.\mathrm{r}_{1}\right)$ of PHPG-DTPA-Gd $\left(15.72 \mathrm{mM}^{-1} \cdot \mathrm{S}^{-1}\right)$ is 3.7 times higher than that of DTPA-Gd (Magnevist ${ }^{\mathrm{T}}$ ). PHPG-DTPA-Gd has excellent blood pool activity. The in vivo MRI of C6 glioblastom-bearing nude mouse exhibited significant enhancement of the tumor periphery after administration of PHPG-DTPA-Gd at a dose of $0.04 \mathrm{mmol} \mathrm{Gd} \mathrm{kg}{ }^{-1}$ via tail vein, and the mouse brain angiography was clearly delineated up to $2 \mathrm{~h}$ after injection of PHPG-DTPA-Gd. Degradation of PHPG-DTPA-Gd by lysosomal enzymes and hydrolysis of side chains lead to complete clearance of Gd-DTPA moieties from the body within $24 \mathrm{~h}$ though the renal route. Shi and coauthors synthesized a Gd-chelated poly(propylene imine) dendrimer composite (PPI-MAL DS-DOTA(Gd)) through chelation of $\mathrm{Gd}^{3+}$ with tetraazacyclododecane tetraacetic acid (DOTA) modified fourth generation poly(propylene imine) (PPI) glycodendrimers (as shown in Figure 3a) [36]. The $\mathrm{r}_{1}$ of PPI-MAL DS-DOTA(Gd) is $10.2 \mathrm{mM}^{-1} \cdot \mathrm{s}^{-1}$, which is 3.0 times higher than that of DOTA $(\mathrm{Gd})\left(3.4 \mathrm{mM}^{-1} \cdot \mathrm{s}^{-1}\right)$. The as-synthesized PPI-MAL DS-DOTA(Gd) can be used as an efficient MRCA for enhanced MRI of blood pool (aorta/renal artery, as shown in Figure $3 b$ ) and organs in vivo. The PPI-MAL DS-DOTA $(\mathrm{Gd})$ exhibits good cytocompatibility and hemocompatibility, which can be metabolized and cleared out of the body at $48 \mathrm{~h}$ post-injection. 
a
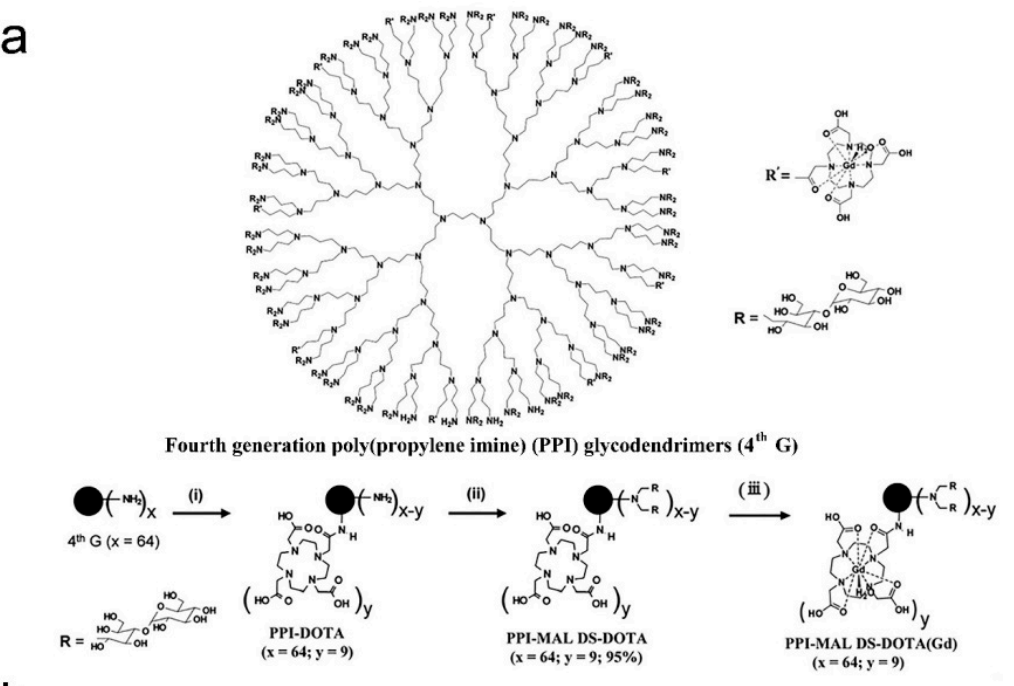

b
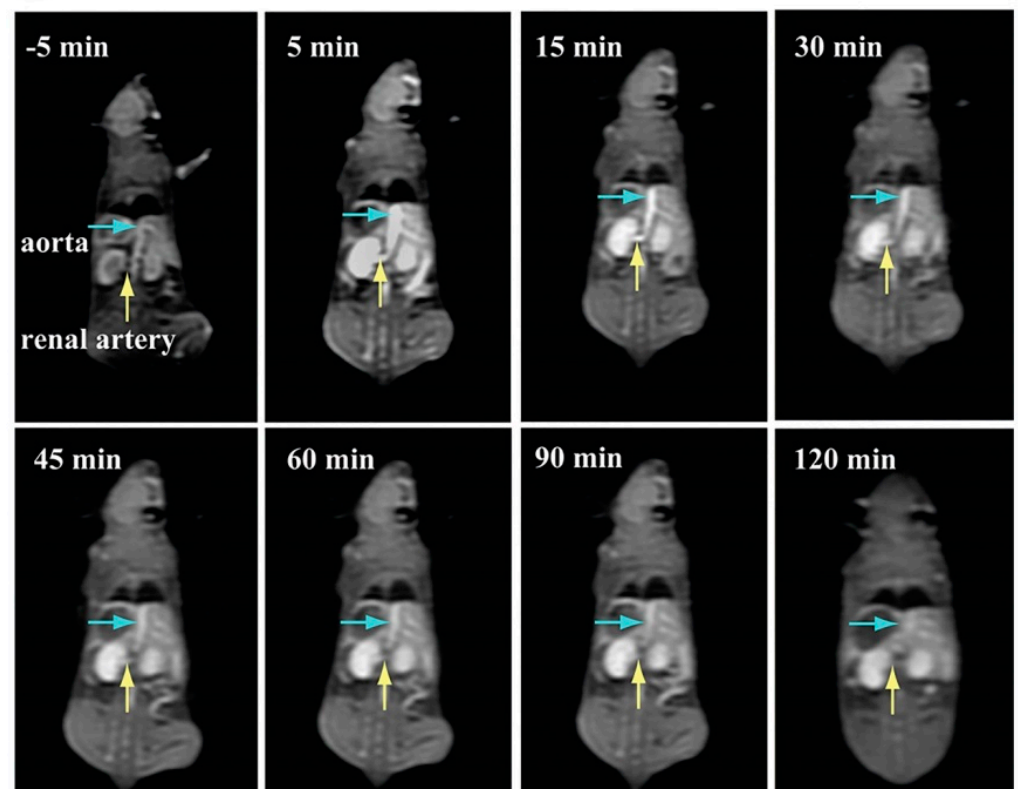

Figure 3. (a) Schematic illustration of the approach used to synthesize the PPI-MAL DS-DOTA(Gd), and (b) $\mathrm{T}_{1}$-weighted MR images of mouse aorta and renal artery at $5 \mathrm{~min}$ before injection $(-5 \mathrm{~min})$ and at $15,30,45,60,90$, and 120 min post-injection of the PPI-MAL DS-DOTA(Gd) $\left(\left[\mathrm{Gd}^{3+}\right]=2 \mathrm{mg} \mathrm{mL}^{-1}\right.$ in $0.2 \mathrm{~mL}$ saline through tail vein, adapted from Shi et al. 2016 [36], Copyright 2016 The Royal Society of Chemistry and reproduced with permission).

In comparison with small molecule $\mathrm{Gd}^{3+}$-complexes, $\mathrm{Gd}^{3+}$-complex-based nanocomposites provide significant advantages for contrast-enhanced MRI such as increased $\mathrm{Gd}^{3+}$ payload, prolonged blood circulation, enhanced $\mathrm{r}_{1}$ and improved uptake of $\mathrm{Gd}^{3+}$ [28-30]. Generally, the contrast efficiency of $\mathrm{Gd}^{3+}$-complex-based nanocomposite is affected by the structure and surface chemistry of the used nanomaterial. For example, the MRI contrast capability of $\mathrm{Gd}^{3+}$-complex-metal-organic framework (MOF) nanocomposite is strongly dependent on the size and pore shape of MOF [38]. Furthermore, the nanocomposites of $\mathrm{Gd}^{3+}$-complexes with NDs not only have relatively long blood circulation time, but also integrate the properties of both $\mathrm{ND}$ and $\mathrm{Gd}^{3+}$-complexes [37-52]. The relatively easy modification property of ND offers opportunities for generation of theranostics for various biomedical applications such as targeted delivery, multimodal imaging, and imaging-guided therapy. For instance, coupling of $\mathrm{Gd}^{3+}$-complexes with optical NDs (e.g., quantum dots (QDs), noble metal nanoclusters, and carbon NDs) we can generate contrast agents for MR/fluorescence dual-mode 
imaging [39,42,44-48]. Using bovine serum albumin (BSA) as templates, Liang and Xiao synthesized Gd-DTPA functionalized gold nanoclusters (BAG), which show intense red fluorescence emission $\left(4.9 \pm 0.8\right.$ quantum yield (\%)) and high $\mathrm{r}_{1}\left(9.7 \mathrm{mM}^{-1} \cdot \mathrm{s}^{-1}\right)$ [47]. The in vivo MRI demonstrates that BAG circulate freely in the blood pool with negligible accumulation in the liver and spleen and can be removed from the body through renal clearance, when BAG were injected intravenously into a Kunming mouse at a dose of $0.008 \mathrm{mmol} \mathrm{Gd} \mathrm{kg}{ }^{-1}$ via the tail vein. The unique properties of BAG make it an ideal dual-mode fluorescence/MR imaging contrast agent, suggesting its potential in practical bioimaging applications in the future. Very recently, Basilion and coauthors constructed a targeted nanocomposite, Au-Gd ${ }^{3+}$-prostate-specific membrane antigen (PSMA) NPs for MRI-guided radiotherapy of prostate cancer by immobilization of the $\mathrm{Gd}^{3+}$-complex and prostate-specific membrane antigen (PSMA) targeting ligands on the monodispersing Au NPs (as shown in Figure 4a) [50]. Because the hydrodynamic diameter of Au-Gd ${ }^{3+}-$ PSMA NPs is $7.8 \mathrm{~nm}, \mathrm{Au}-\mathrm{Gd}^{3+}-\mathrm{PSMA}$ NPs enable efficient accumulation into the tumor site through the EPR effect and ligand-antigen binding, and can be excreted through the renal route. The $r_{1}$ of Au-Gd ${ }^{3+}-$ PSMA NPs $\left(20.6 \mathrm{mM}^{-1} \cdot \mathrm{s}^{-1}\right)$ is much higher than that of free $\mathrm{Gd}^{3+}$-complexes $\left(5.5 \mathrm{mM}^{-1} \cdot \mathrm{s}^{-1}\right)$. In addition, both of the $\mathrm{Au}$ and $\mathrm{Gd}^{3+}$ atoms can serve as sensitizers of radiotherapy. The Au-Gd ${ }^{3+}$-PSMA NPs show good tumor-targeting specificity, high MR contrast, significant in vivo radiation dose amplification, and renal clearance ability, which exhibit great potential in the clinical MR-guided radiotherapy of PSMA-positive solid tumors ((as shown in Figure $4 b)$.

a

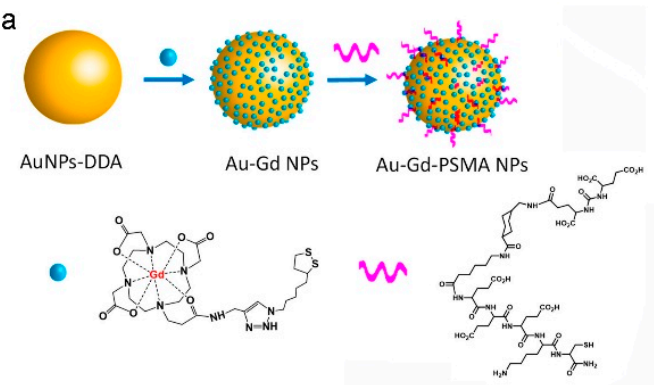

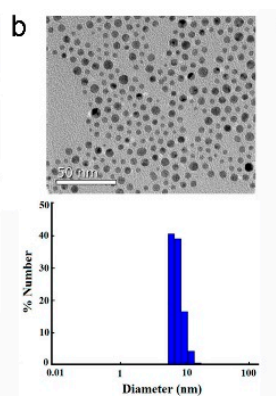

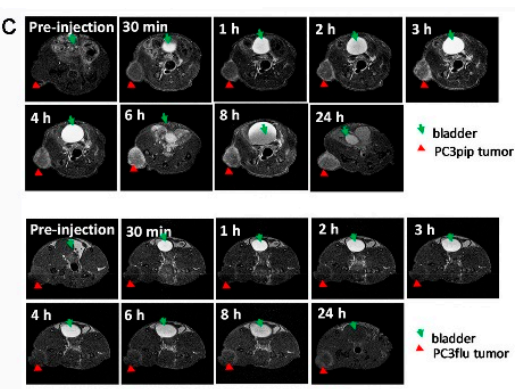

Figure 4. $\mathrm{Au}_{-} \mathrm{Gd}^{3+}$-prostate-specific membrane antigen (PSMA) NPs for MR-guided radiation therapy. (a) Schematic representation of Au-Gd ${ }^{3+}$-PSMA NPs. (b) TEM micrograph indicates that the average core size of Au-Gd ${ }^{3+}-$ PSMA NPs is $5 \mathrm{~nm}$, and DLS shows that the hydrodynamic diameter of Au-Gd ${ }^{3+}$-PSMA NPs is $7.8 \mathrm{~nm}$. (c) In vivo tumor targeting of Au-Gd ${ }^{3+}$-PSMA NPs and MR imaging of PC3pip tumor-bearing mouse (up) and PC3flu tumor-bearing mouse (bottom) obtained at $7 \mathrm{~T}$. PC3pip tumor cell expresses high level of PSMA, while PC3flu tumor cell expresses low level of PSMA (the mice were injected with Au-Gd ${ }^{3+}$-PSMA NPs at $60 \mu \mathrm{mol} \mathrm{Gd}{ }^{3+} \cdot \mathrm{kg}^{-1}$ through the tail vein, adapted from Basilion et al. 2020 [50], Copyright 2020 The American Chemical Society and reproduced with permission).

As a rising star of carbon nanomaterial, carbon quantum dots (CDs) have drawn tremendous attention because of their excellent optical property, high physicochemical stability, good biocompatibility, and the ease of surface functionalization [53-57]. Recently, various $\mathrm{Gd}^{3+}$-doped $\mathrm{CDs}(\mathrm{Gd}-\mathrm{CD})$ have been synthesized for fluorescence/MR dual-mode imaging by the low temperature pyrolysis of precursors containing $\mathrm{Gd}^{3+}$ (such as $\mathrm{Gd}^{3+}$-complexes) and carbon [58-61]. Zou and coauthors reported Gd-CD-based theranostics for MRI-guided radiotherapy of a tumor (as shown in Figure 5) [58]. The Gd-CDs were synthesized through a one-pot pyrolysis of glycine and Gd-DTPA at $180^{\circ} \mathrm{C}$, which exhibited stable photoluminescence (PL) at the visible region, relatively long circulation time $(\sim 6 \mathrm{~h})$, and efficient passive tumor-targeting ability. The $\mathrm{r}_{1}$ value of Gd-CDs was calculated to be $6.45 \mathrm{mM}^{-1} \cdot \mathrm{s}^{-1}$, which was higher than that of Magnevist ${ }^{\mathrm{T}}\left(4.05 \mathrm{mM}^{-1} \cdot \mathrm{s}^{-1}\right)$ under the same conditions. An in vivo experiment demonstrated that the Gd-CDs could provide better anatomical and pathophysiologic detection of tumor and precisely positioning for MRI-guided radiotherapy, when the 
mice were injected intravenously with the Gd-CD solution at a dose of $10 \mathrm{mg} \mathrm{Gd} \mathrm{kg}{ }^{-1}$. In addition, the efficient renal clearance of Gd-CDs meant it was finally excreted from the body by urine.

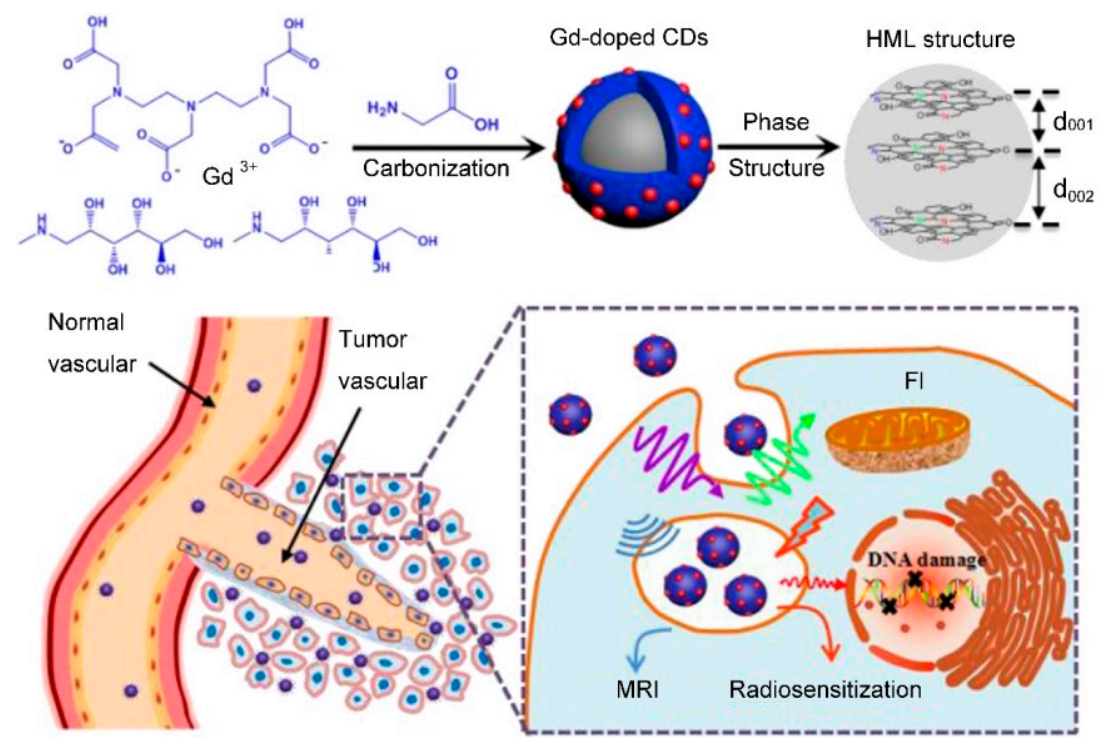

Figure 5. Schematic synthesis and application of Gd-doped CDs through one-pot pyrolysis of glycine and Gd-DTPA at $180{ }^{\circ} \mathrm{C}$ (adapted from Zou et al. 2017 [58], Copyright 2017 The Elsevier Ltd. and reproduced with permission).

\section{Paramagnetic Metal Nanodots}

During the last two decades, several MNDs have been synthesized and used as MRCAs because of their advanced imaging properties compared to small molecule $\mathrm{Gd}^{3+}$-complexes. For example, the MNDs exhibit high surface-to-volume ratios, which allow the ${ }^{1} \mathrm{H}$ to interact with a large number of paramagnetic ions in a tiny volume, resulting in high signal-to-noise ratios at ROI. It has been demonstrated that the size of MND is directly associated with the MRI contrast capability, biodistribution, blood circulation time, and clearance rate $[5,14,15,18,23,25,27]$. In order to finely control over the aforementioned parameters, the as-developed MND-based MRCAs for clinical applications are highly required to be monodisperse. The hydrophilic MNDs can be directly synthesized through reactions of paramagnetic metal ionic precursors with hydrophilic coating/functionalizing agents. Although this approach is simple and direct, it is difficult to control size and uniformity of MNDs in the aqueous synthetic methods. In order to achieve narrow size distribution and low crystalline defect, most of the MNDs are synthesized by nonaqueous synthesis routes. Because of their inherent hydrophobicity, MNDs should be coated/functionalized with hydrophilic and biocompatible ligands (shells) for biomedical applications. The post-synthetic modification strategies generally involve ligand exchange with hydrophilic molecules as well as encapsulation by hydrophilic shells.

\subsection{Gadolinium Nanodots}

Generally, there are two protocols for the synthesis of inorganic $\mathrm{Gd}^{3+} \mathrm{NDs}$ : (1) direct synthesis of hydrophilic $\mathrm{Gd}^{3+} \mathrm{NDs}$ in water or polyol using a stabilizing agent which allows for crystal growth, followed by ligand exchange with a more robust stabilizing agent to improve the colloidal stability of $\mathrm{Gd}^{3+} \mathrm{NDs}$ in complex matrixes [62-81], and (2) preparation of hydrophobic $\mathrm{Gd}^{3+} \mathrm{NDs}$ in high boiling organic solvents by the pyrolysis methods, and subsequent transfer of the hydrophobic $\mathrm{Gd}^{3+} \mathrm{NDs}$ into aqueous phase by using a hydrophilic/amphiphilic ligand to render them water-dispersible [82-90]. 


\subsubsection{Gadolinium Oxide Nanodots}

Several methods have been developed to synthesize $\mathrm{Gd}_{2} \mathrm{O}_{3}$ NDs for the application in MRCAs [62-72,74,77-80]. As early as 2006, Uvdal and coauthors synthesized $\mathrm{Gd}_{2} \mathrm{O}_{3} \mathrm{NDs}$ (5 to $10 \mathrm{~nm}$ in diameter) by thermal decomposition of $\mathrm{Gd}^{3+}$ precursors $\left(\mathrm{Gd}\left(\mathrm{NO}_{3}\right)_{3} \cdot 6 \mathrm{H}_{2} \mathrm{O}\right.$ or $\left.\mathrm{GdCl}_{3} \cdot 6 \mathrm{H}_{2} \mathrm{O}\right)$ in the diethylene glycol (DEG) [62]. Both $\mathrm{r}_{1}$ and $\mathrm{r}_{2}$ of the DEG capped $\mathrm{Gd}_{2} \mathrm{O}_{3} \mathrm{NDs}$ are approximately 2 times higher than those of Gd-DTPA. Lee's group developed a one-pot synthesis method with two steps for preparing a series of hydrophilic $\mathrm{Gd}_{2} \mathrm{O}_{3}$ NDs with high colloidal stability: (1) using $\mathrm{GdCl}_{3} \cdot 6 \mathrm{H}_{2} \mathrm{O}$ as $\mathrm{Gd}^{3+}$ as precursors, $\mathrm{Gd}_{2} \mathrm{O}_{3} \mathrm{NDs}$ were firstly synthesized in tripropylene/triethylene glycol (TPG/TEG) under alkaline condition, and aged by $\mathrm{H}_{2} \mathrm{O}_{2}$ and/or an $\mathrm{O}_{2}$ flow; (2) the as-prepared $\mathrm{Gd}_{2} \mathrm{O}_{3}$ NDs were then stabilized by different coating materials including amino acid, polymers, and carbon [63-70]. As early as 2009, Lee and coauthors synthesized D-glucuronic acid coated $\mathrm{Gd}_{2} \mathrm{O}_{3}$ NDs in TPG by using D-glucuronic acid as stabilizer [63]. The D-glucuronic acid coated $\mathrm{Gd}_{2} \mathrm{O}_{3} \mathrm{NDs}$ with $1.0 \mathrm{~nm}$ in diameter have a high $\mathrm{r}_{1}\left(9.9 \mathrm{mM}^{-1} \cdot \mathrm{s}^{-1}\right)$, which can easily cross the brain-blood barrier (BBB), causing a strong contrast enhancement in the brain tumor within two hours. Due to the excretion of the injected D-glucuronic acid coated $\mathrm{Gd}_{2} \mathrm{O}_{3}$ NDs, the MRI contrast began to decrease at $2 \mathrm{~h}$ post-injection. The in vivo MR images of brain tumor, kidney, bladder, and aorta demonstrate that D-glucuronic acid coated $\mathrm{Gd}_{2} \mathrm{O}_{3}$ NDs have good tumor-targeting ability, strong blood pool effect, and high renal clearance when the mice were injected intravenously $\mathrm{Gd}_{2} \mathrm{O}_{3} \mathrm{NDs}_{\text {solution a }}$ dose of $0.07 \mathrm{mmol} \mathrm{Gd} \mathrm{kg}{ }^{-1}$. Subsequently, Lee and coauthors successfully synthesized hydrophilic polyacrylic acid (PAA) coated $\mathrm{Gd}_{2} \mathrm{O}_{3} \mathrm{NDs}$ (average diameter $=2.0 \mathrm{~nm}$ ) with high biocompatibility by electrostatically binding of $-\mathrm{COO}^{-}$groups of PAA with $\mathrm{Gd}^{3+}$ on the $\mathrm{Gd}_{2} \mathrm{O}_{3} \mathrm{NDs}$ (as shown in Figure 6) [69]. Because the magnetic dipole interaction between surface $\mathrm{Gd}^{3+}$ and ${ }^{1} \mathrm{H}$ is impeded by the PAA, both $r_{1}$ and $r_{2}$ values of $\mathrm{Gd}_{2} \mathrm{O}_{3}$ NDs are decreased with increasing the molecular weight of PAA (Mw = 1200, 5100 and 15,000 Da). Very recently, Lee and coauthors synthesized a kind of carbon-coated $\mathrm{Gd}_{2} \mathrm{O}_{3} \mathrm{NDs}\left(\mathrm{Gd}_{2} \mathrm{O}_{3} @ \mathrm{C}\right.$, average diameter $\left.=3.1 \mathrm{~nm}\right)$ by using dextrose as a carbon source in the aqueous solution (as shown in Figure 7) [70]. The $\mathrm{Gd}_{2} \mathrm{O}_{3} @ \mathrm{C}$ have excellent colloidal stability, very high $\mathrm{r}_{1}$ value $\left(16.26 \mathrm{mM}^{-1} \cdot \mathrm{s}^{-1}, \mathrm{r}_{2} / \mathrm{r}_{1}=1.48\right)$, and strong photoluminescence (PL) in the visible region, which can be used as renal clearable MR/PL dual-mode imaging agent.

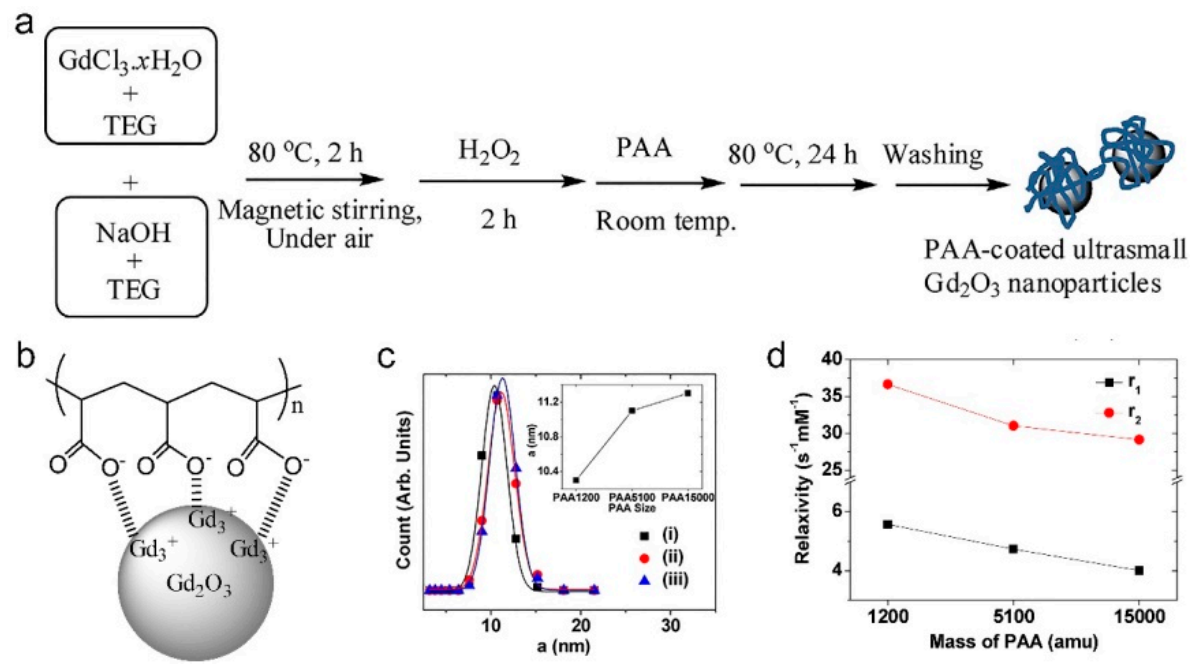

Figure 6. (a) Schematic representation of the one-pot synthesis of polyacrylic acid (PAA) coated $\mathrm{Gd}_{2} \mathrm{O}_{3}$ NDs, (b) the representative PAA surface-coating structure, (c) DLS measurement of (i) PAA 1200, (ii) PAA 5100, and (iii) PAA 15,000 coated $\mathrm{Gd}_{2} \mathrm{O}_{3}$ NDs, inset of (c) is the hydrodynamic diameter of PAA coated $\mathrm{Gd}_{2} \mathrm{O}_{3}$ NDs as a function of PAA molecular weight, and (d) $r_{1}$ and $r_{2}$ values as a function of PAA molecular weight (adapted from Lee et al. 2019 [69], Copyright 2017 the Elsevier B.V. and reproduced with permission). 
a (I)

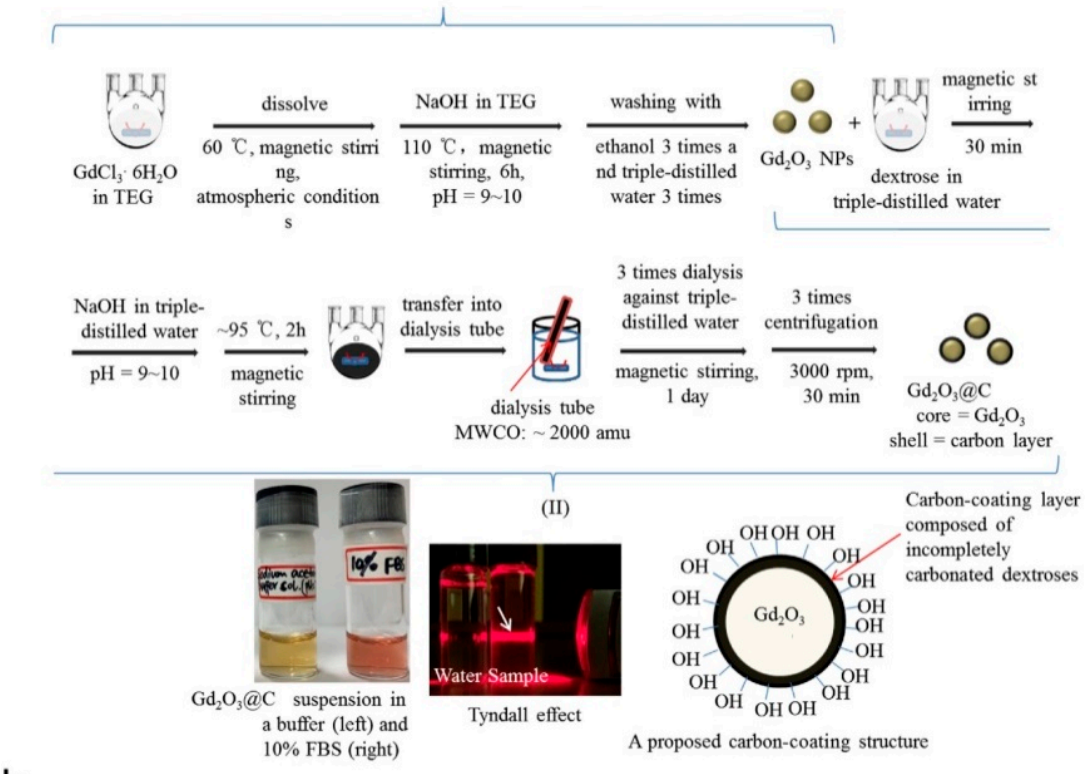

b

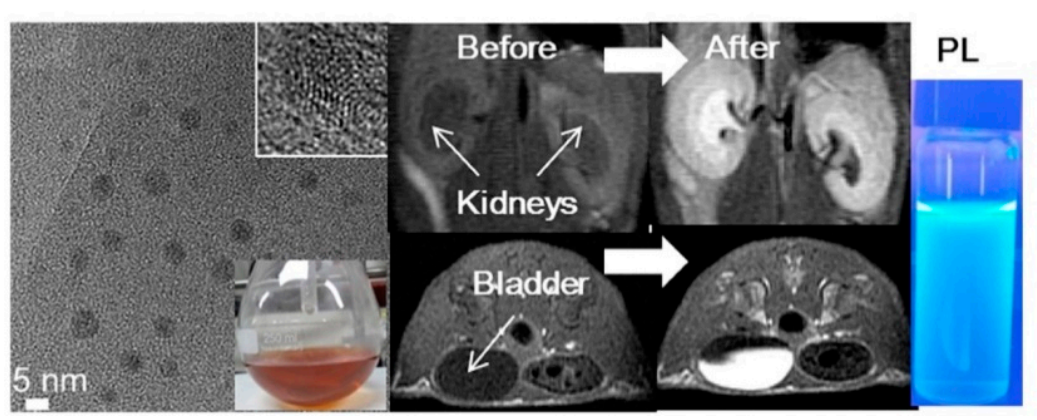

Figure 7. (a) Two-step synthesis of $\mathrm{Gd}_{2} \mathrm{O}_{3} @ \mathrm{C}$ : (i) the synthesis of $\mathrm{Gd}_{2} \mathrm{O}_{3}$ NDs in triethylene glycol (TEG), and (ii) carbon coating on the $\mathrm{Gd}_{2} \mathrm{O}_{3} \mathrm{ND}$ surfaces in aqueous solution. From left to right at the bottom of (a), photographs of the $\mathrm{Gd}_{2} \mathrm{O}_{3} @ \mathrm{C}$ in sodium acetate buffer solution $(\mathrm{pH}=7.0)$ and a $10 \%$ FBS in RPMI1640 medium, the Tyndall effect (or laser light scattering) as indicated with an arrow in the $\mathrm{Gd}_{2} \mathrm{O}_{3} @ \mathrm{C}$ in water sample (right) with no light scattering in the reference triple-distilled water (left), and a proposed carbon-coating structure of $\mathrm{Gd}_{2} \mathrm{O}_{3} @ \mathrm{C}$. (b) High resolution transmission electron microscope (HRTEM) micrograph of $\mathrm{Gd}_{2} \mathrm{O}_{3} @ \mathrm{C}$, photograph of $\mathrm{Gd}_{2} \mathrm{O}_{3} @ \mathrm{C}$ in water, in vivo MRI of mouse before or after intravenously administrated by $\mathrm{Gd}_{2} \mathrm{O}_{3} @ \mathrm{C}$ and PL of $\mathrm{Gd}_{2} \mathrm{O}_{3} @ \mathrm{C}$ at a dose of $0.1 \mathrm{mmol} \mathrm{Gd} \mathrm{kg}^{-1}$ (adapted from Lee et al. 2020 [70], Copyright 2019 the Elsevier B.V. and reproduced with permission).

\subsection{2. $\mathrm{NaGdF}_{4}$ Nanodots}

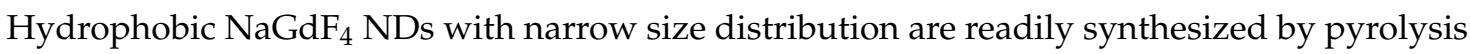
methods via a high boiling binary solvent mixture [82-89]. In the presence of oleic acid, the approach has been demonstrated to be able to produce $\mathrm{NaGdF}_{4} \mathrm{NDs}$ with high quality (e.g., low crystal defect and good monodispersity) through the thermal decomposition of $\mathrm{Gd}^{3+}$ precursors, $\mathrm{NaOH}$, and $\mathrm{NH}_{4} \mathrm{~F}$ in octadecene. In order to transfer the as-prepared hydrophobic $\mathrm{NaGdF}_{4} \mathrm{NDs}$ into aqueous phase,

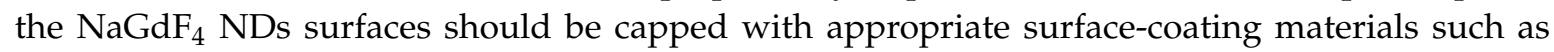
amphiphilic polymers and biomacromolecules. As early as 2011, Veggel and coauthors reported a size-selective synthesis of paramagnetic $\mathrm{NaGdF}_{4} \mathrm{NPs}$ with four different sizes (between 2.5 and $8.0 \mathrm{~nm}$ in diameter) with good monodispersity by adjusting the concentration of the coordinating ligand (i.e., oleic acid), reaction time, and temperature [82]. The oleate coated $\mathrm{NaGdF}_{4} \mathrm{NPs}_{\text {were }}$ then transferred into aqueous phase by using polyvinylpyrrolidone (PVP) as phase transfer agent. They found that the $r_{1}$ values of PVP coated $\mathrm{NaGdF}_{4} \mathrm{NPs}$ are decreased from 7.2 to $3.0 \mathrm{mM}^{-1} \cdot \mathrm{s}^{-1}$ with 
increasing the NP size from 2.5 to $8.0 \mathrm{~nm}$. In particular, the $\mathrm{r}_{1}$ value of PVP coated $2.5 \mathrm{~nm} \mathrm{NaGdF} 4$ NDs is about twice as high as that of Magnevist ${ }^{\mathrm{T}}$ under same conditions.

Shi and coauthors successfully employed the amphiphilic molecule, PEG-phospholipids, (such as DSPE-PEG $_{2000}$ (1,2-Distearoyl-sn-glycero-3-phosphoethanolamine-Poly(ethylene glycol) 2000 ) and/or the mixture of DSPE-PEG 2000 and DSPE-PEG $2000-\mathrm{NH}_{2}$ (amine functionalized DSPE-PEG 2000 )) to

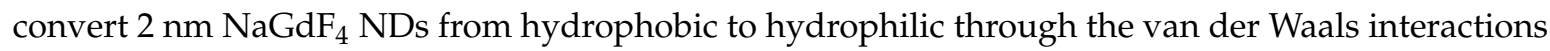
of the two hydrophobic tails of phospholipid groups of PEG-phospholipids and the oleic acids on the ND surface $[84,85]$. The PEG-phospholipids/amine functionalized PEG-phospholipids coated $\mathrm{NaGdF}_{4} \mathrm{NDs}_{\text {can }}$ be further functionalized by other molecules via suitable physical and chemical reactions. For example, poly-L-lysine (PLL) coated $\mathrm{NaGdF}_{4} \mathrm{NDs}\left(\mathrm{NaGdF}_{4} @ P L L\right.$ NDs) were developed as dual-mode MRCA by layer-by-layer (LbL) self-assembly of positively charged PLL on the negatively charged DSPE-PEG ${ }_{5000}$ coated $\mathrm{NaGdF}_{4} \mathrm{NDs}$ (as shown in Figure 8) [85]. The $\mathrm{NaGdF}_{4} @ P L L$ ND exhibits high $\mathrm{r}_{1}\left(6.42 \mathrm{mM}^{-1} \cdot \mathrm{s}^{-1}\right)$ for $\mathrm{T}_{1}$-weighted MRI, while the PLL shows an excellent sensitive chemical exchange saturation transfer (CEST) effect for $\mathrm{pH}$ mapping (at $+3.7 \mathrm{ppm})$. The results of in vivo small animal experiments demonstrate that $\mathrm{NaGdF}_{4} @ P L L$ NDs can be used as highly efficient MRCA for precise measurement of in vivo $\mathrm{pH}$ value and diagnosis of kidney and brain tumor. Moreover, the $\mathrm{NaGdF}_{4} @ P L L$ NDs could be excreted through urine with negligible toxicity to body tissues, which holds great promise for future clinical applications.

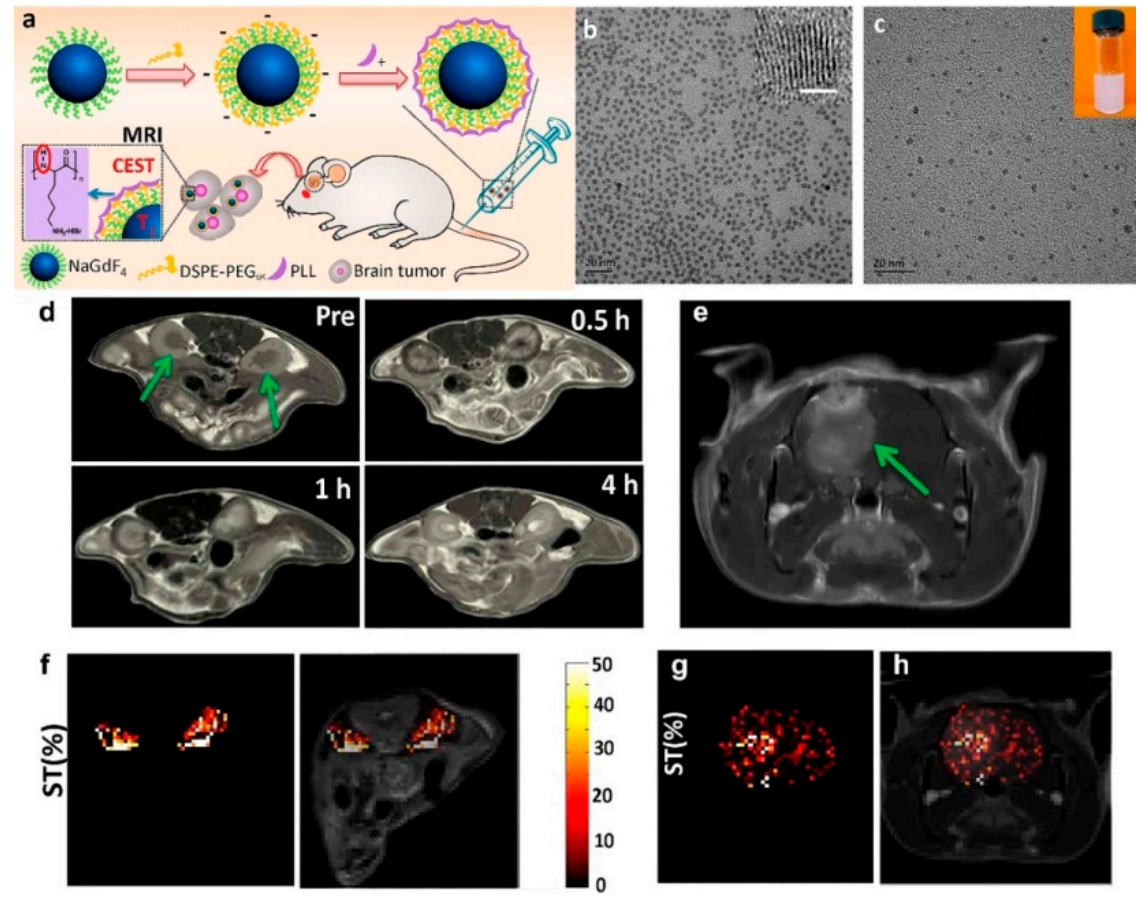

Figure 8. (a) Schematic representation of the synthesis of $\mathrm{NaGdF}_{4} @ P L L$ NDs for $\mathrm{T}_{1}$-weighted and chemical exchange saturation transfer (CEST) MR imaging. (b) TEM and HRTEM (inset, scale bar: $1 \mathrm{~nm}$ ) micrograph oleic acid-coated $\mathrm{NaGdF}_{4} \mathrm{NDs}$ in chloroform. (c) TEM micrograph and photograph (inset) of $\mathrm{NaGdF}_{4} @ P L L$ NDs in water. (d) In vivo $\mathrm{T}_{1}$-weighted MRI of kidneys of mouse (as arrowed) before and after the intravenous administration of $\mathrm{NaGdF}_{4} @ P L L$ NDs at a dose of $5 \mathrm{mg} \mathrm{Gd} \mathrm{kg}^{-1}$. (e) In vivo $\mathrm{T}_{1}$-weighted MRI of brain tumor (as arrowed) after the intravenous administration of $\mathrm{NaGdF}_{4} @ P L L$ NDs at a dose of $10 \mathrm{mg} \mathrm{Gd} \mathrm{kg}^{-1}$. (f) CEST contrast difference map between pre/post-injection following radio frequency $(\mathrm{RF})$ irradiation at $3.0 \mu \mathrm{T}$. Only the kidney signal is displayed in color on the grayscale image to highlight the CEST effect. (g) CEST ST difference map between pre/post-injection at $3.0 \mu \mathrm{T}$. Only the brain ventricle signal is displayed in color on the grayscale image to highlight the CEST effect. (h) Merged image of (e) and (g) (adapted from Shi et al. 2016 [85], Copyright 2016 the American Chemical Society and reproduced with permission). 
Taking benefit from robust $\mathrm{Gd}^{3+}$-phosphate coordination bonds, our group developed a facile method for transferring hydrophobic $\mathrm{NaGdF}_{4} \mathrm{NDs}$ into aqueous phase though ligand exchange reaction between oleate and phosphopeptides in tryptone [86,87]. The tryptone-coated $\mathrm{NaGdF}_{4}$ NDs (tryptone- $\mathrm{NaGdF}_{4} \mathrm{NDs}$ ) have excellent colloidal stability, low toxicity, outstanding MRI enhancing performance $\left(\mathrm{r}_{1}=6.745 \mathrm{mM}^{-1} \cdot \mathrm{s}^{-1}\right)$, efficient renal clearance, and EPR effect-based passive tumor-targeting ability. Importantly, the tryptone- $\mathrm{NaGdF}_{4} \mathrm{NDs}$ can be easily functionalized by other molecules including organic dyes and bioaffinity ligands. As shown in Figure 9, the tryptone-NaGdF 4 NDs were further functionalized by hyaluronic acid (HA, a naturally occurring glycosaminoglycan) [87]. The HA functionalized tryptone- $\mathrm{NaGdF}_{4}$ NDs (tryptone- $\mathrm{NaGdF}_{4} \mathrm{ND@HAs)} \mathrm{exhibit} \mathrm{high} \mathrm{binding}$ affinity with CD44-positive cancer cells, good paramagnetic property $\left(\mathrm{r}_{1}=7.57 \mathrm{mM}^{-1} \cdot \mathrm{s}^{-1}\right)$ and reasonable biocompatibility. Using MDA-MB-231 tumor-bearing mouse as a model, the in vivo experimental results demonstrate that the tryptone- $\mathrm{NaGdF}_{4} \mathrm{ND} @ \mathrm{HAs}$ cannot only efficiently accumulate in tumor (ca. 5.3\% injection dosage (ID) $\mathrm{g}^{-1}$ at $2 \mathrm{~h}$ post-injection), but also have an excellent renal clearance efficiency (ca. $75 \%$ ID at $24 \mathrm{~h}$ post-injection). The approach provides a useful strategy for the preparation of renal clearable MRCAs with positive tumor-targeting ability. Using a similar phase transferring principle, the peptide functionalized $\mathrm{NaGdF}_{4} \mathrm{NDs}$ (pPeptide- $\mathrm{NaGdF}_{4} \mathrm{NDs}$ ) were prepared by conjugation of the hydrophobic oleate coated $\mathrm{NaGdF}_{4} \mathrm{NDs}$ ( $4.2 \mathrm{~nm}$ in diameter) with the mixture of phosphorylated peptides including a tumor targeting phosphopeptide (pD-SP5) and a cell penetrating phosphopeptide (pCLIP6) [88]. Due to its high isoelectric point, the pCLIP6 can enhanced the cellular uptake of pPeptide- $\mathrm{NaGdF}_{4}$ NDs. The pD-SP5 can improve the tumor-targeting

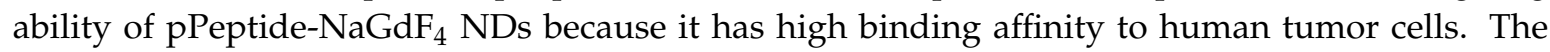
pPeptide-NaGdF $\mathrm{NDs}_{4} \mathrm{Nhow}$ low toxicity, outstanding MRI enhancing performance $\left(\mathrm{r}_{1}=13.2 \mathrm{mM} \mathrm{m}^{-1} \cdot \mathrm{s}^{-1}\right)$ and positive-tumor targeting ability, which were used successfully as efficient MRCA for an in vivo imaging small drug induced orthotopic colorectal tumor (c.a., $195 \mathrm{~mm}^{3}$ ), when the mice were then intravenously injected with pPeptide-NaGdF 4 NDs at a dose of $5 \mathrm{mg} \mathrm{Gd} \mathrm{kg}^{-1}$. In addition, the half-life of pPeptide-NaGdF $\mathrm{NDs}_{4}$ in blood is found to be $0.5 \mathrm{~h}$, and more than $70 \% \mathrm{Gd}$ is excreted with the urine after $24 \mathrm{~h}$ intravenous administration. 

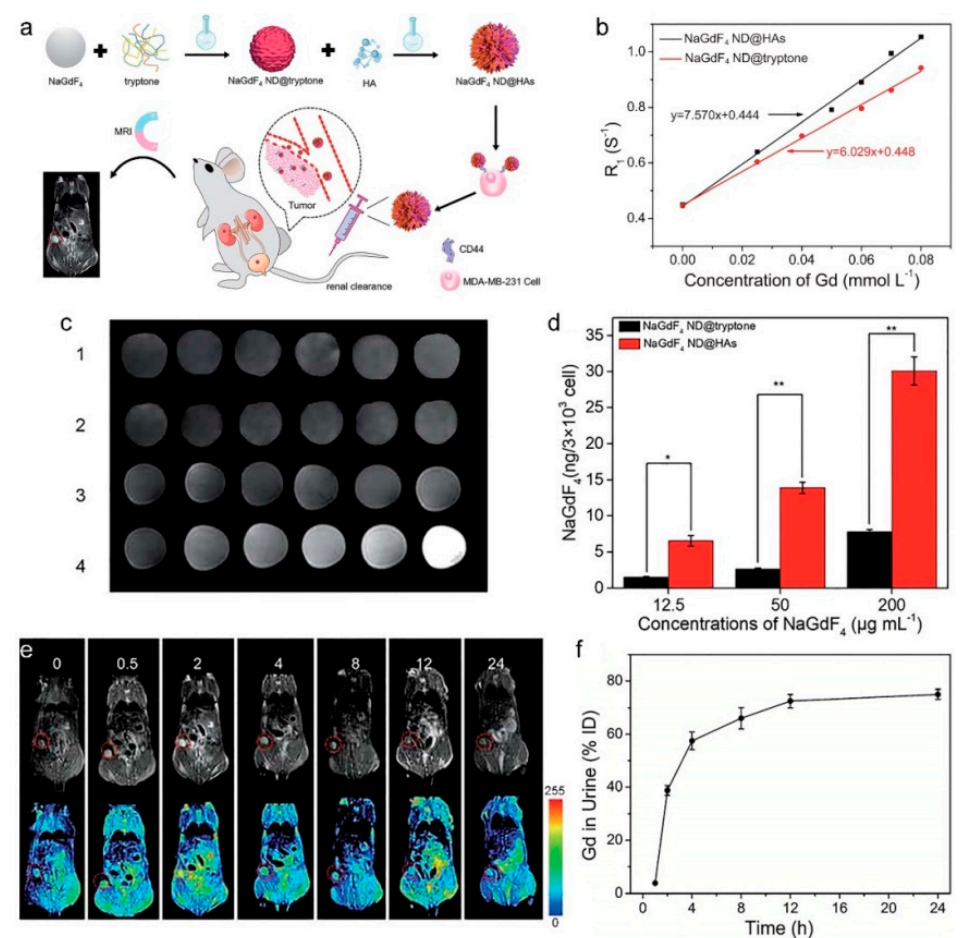

Figure 9. (a) Schematic representation of $\mathrm{NaGdF}_{4} \mathrm{ND@HAs}$ synthesis, and the application in MRI of tumor through recognizing the overexpressed CD44 on cancer cell membrane. (b) $\mathrm{R}_{1}$ relaxivities of $\mathrm{NaGdF}_{4} \mathrm{ND@tryptone} \mathrm{and} \mathrm{NaGdF}_{4} \mathrm{ND@HAs}$ as a function of the molar concentration of $\mathrm{Gd}^{3+}$ in solution, respectively. (c) MR images of (1) $\mathrm{NaGdF}_{4} \mathrm{ND} @ H A$-stained MCF-7 cells, (2) free HA + MDA-MB-231 cells + NaGdF $\mathrm{ND}_{4} @ H A s,(3) \mathrm{NaGdF}_{4}$ ND@tryptone-stained MDA-MB-231 cells, (4) $\mathrm{NaGdF}_{4} \mathrm{ND@HA-stained} \mathrm{MDAMB-231} \mathrm{cells.} \mathrm{(d)} \mathrm{The} \mathrm{amounts} \mathrm{of} \mathrm{Gd} \mathrm{element} \mathrm{in} \mathrm{the} \mathrm{NaGdF}_{4}$ ND-stained MDA-MB-231cells. Error bars mean standard deviations $\left(n=5,{ }^{*} p<0.05\right.$ or ${ }^{* *} p<0.01$ from an analysis of variance with Tukey's post-test). (e) In vivo MR images and corresponding pseudo color images of Balb/c mouse bearing MDA-MB-231 tumor after intravenous injection of $\mathrm{NaGdF}_{4} \mathrm{ND} @ \mathrm{HAs}$ (10 $\left.\mathrm{mg} \mathrm{Gd} \mathrm{kg}^{-1}\right)$ at different timed intervals (0 (pre-injection), 0.5, 2, 4, 8, 12 and $24 \mathrm{~h}$ post-injection), respectively. (f) The total amounts of $\mathrm{NaGdF}_{4} \mathrm{ND} @ \mathrm{HAs}$ in mouse urine as a function of post-injection times. Error bars mean standard deviations $(n=5)$ (adapted from Yan et al. 2020 [87], Copyright 2020 The Royal Society of Chemistry and reproduced with permission).

\subsection{Iron Nanodots}

In 1996, the U. S. FDA approved Ferumoxides (SPIONs) as $\mathrm{T}_{2}$-weighted MR CAs for the diagnosis of liver disease [91]. After that, various strategies based on physical, chemical, and biological methods have been developed for synthesizing the SPIONs including FeNDs for using as $\mathrm{T}_{2}$-weighted MRCAs [91-95]. Because of the negative contrast effect and magnetic susceptibility artifacts, it is still a great challenge when the SPION-enhanced $\mathrm{T}_{2}$-weighted MRI is employed to distinguish the lesion region in the tissues with low background MR signals such as bone and vasculature. Recently, several methods have developed for synthesis of FeNDs, which are showing increasing potential as alternatives to $\mathrm{Gd}^{3+}$-based $\mathrm{T}_{1}$-weighted MRCAs because of low magnetization by a strong size-related surface spin-canting effect [96-111]. For instance, Wu and coauthors synthesized a silica-coated $\mathrm{Fe}_{3} \mathrm{O}_{4}$ $\mathrm{ND}$ (4 nm in diameter), which exhibited a good $\mathrm{r}_{1}$ relaxivity of $1.2 \mathrm{mM}^{-1} \cdot \mathrm{s}^{-1}$ with a low $\mathrm{r}_{2} / \mathrm{r}_{1}$ ratio of 6.5 [101]. The result of in vivo $\mathrm{T}_{1}$-weighted MR imaging of heart, liver, kidney, and bladder in a mouse demonstrated that silica-coated FeNDs exhibited strong MR enhancement capability, when the mice were then intravenously injected with silica-coated FeNDs at a dose of $2.8 \mathrm{mg} \mathrm{Fe} \mathrm{kg}^{-1}$. Shi and coauthors reported a zwitterion L-cysteine (Cys) coated $\mathrm{Fe}_{3} \mathrm{O}_{4} \mathrm{ND}$ (3.2 nm in diameter, $\mathrm{Fe}_{3} \mathrm{O}_{4}$-PEG-Cys) with $\mathrm{r}_{1}$ relaxivity of $1.2 \mathrm{mM}^{-1} \cdot \mathrm{s}^{-1}$ [102]. The $\mathrm{Fe}_{3} \mathrm{O}_{4}$-PEG-Cys are able to resist macrophage cellular uptake, and display a prolonged blood circulation time with a half-life of $6.2 \mathrm{~h}$. In vivo experimental results 
demonstrated that the $\mathrm{Fe}_{3} \mathrm{O}_{4}$-PEG-Cys were able to be used as a $\mathrm{T}_{1}$-weighted MRCA for enhanced blood pool and tumor MR imaging, when the mice were then intravenously injected with $\mathrm{Fe}_{3} \mathrm{O}_{4}$-PEG-Cys

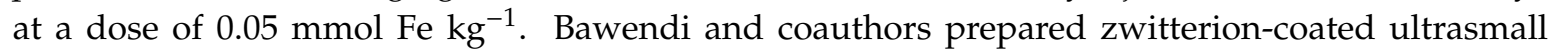
superparamagnetic $\mathrm{Fe}_{2} \mathrm{O}_{3}$ NDs (ZES-SPIONs) with hydrodynamic size of $5.5 \mathrm{~nm}$ for use as Gd ${ }^{3+}$ free $\mathrm{T}_{1}$-weighted MRCA [103]. The ZES-SPIONs have strong $\mathrm{T}_{1}$-weighted MRI enhancement capacity $\left(r_{1}=5.2 \mathrm{mM}^{-1} \cdot \mathrm{s}^{-1}\right)$, and the majority of ZES-SPIONs are cleared through the renal route within $24 \mathrm{~h}$ intravenous administration at a dose of $0.2 \mathrm{mmol} \mathrm{Fe} \mathrm{kg}^{-1}$. As shown in Figure 10, Zhang and coauthors reported a large-scalable (up to $10 \mathrm{~L}$ ) albumin-constrained strategy to synthesize monodispersed $3 \mathrm{~nm}$ ferrous sulfide NDs (FeS@BSA) with an ultralow magnetization by reaction of the mixture of BSA and $\mathrm{FeCl}_{2}$ with $\mathrm{Na}_{2} \mathrm{~S}$ under ambient conditions ( $\mathrm{pH} 11$ and $37^{\circ} \mathrm{C}$ ) [104]. In this case, BSA plays crucial roles in the synthesis process including as a constrained microenvironment reactor for particle growth, a water-soluble ligand for colloidal stability, and a carrier for multifunctionality. FeS@BSAs exhibit high MRI enhancing performance $\left(\mathrm{r}_{1}=5.35 \mathrm{mM}^{-1} \cdot \mathrm{s}^{-1}\right)$, good photothermal conversion efficiency $(\eta=30.04 \%)$, strong tumor-targeting ability, and an efficient renal clearance characteristic. In vivo experiments show that FeS@BSAs have good performance of $\mathrm{T}_{1}$-weighted MR/phototheranostics dual-mode imaging-guided photothermal therapy (PTT) of mouse-bearing 4T1 tumor, demonstrating FeS@BSA to be an efficient $\mathrm{T}_{1}$-weighted MR/PA/PTT theranostic agent.
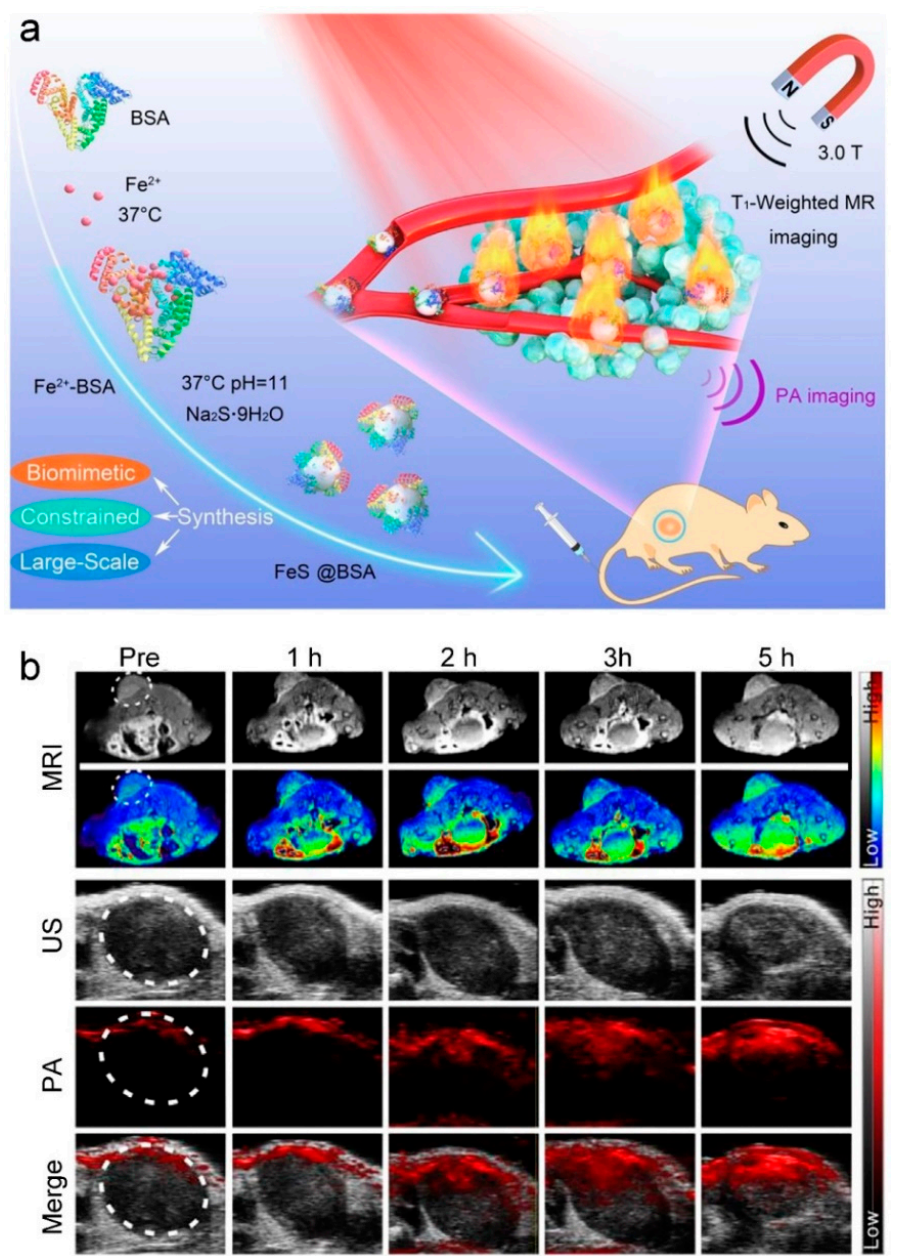

Figure 10. (a) Schematic representation of bovine serum albumin (BSA)-constrained biomimetic synthesis of $3 \mathrm{~nm}$ FeS@BSA for in vivo $\mathrm{T}_{1}$-weighted MR/phototheranostics dual-mode imaging-guided photothermal therapy (PTT) of tumors. (b) In vivo $\mathrm{T}_{1}$-weighted MR, US, PA, and merged (US and PA) images of tumor after intravenous injection of at a dose of $20 \mathrm{mg} \mathrm{FeS@BSA} \mathrm{kg}^{-1}$ (adapted from Zhang et al. 2020 [104], Copyright 2020 Elsevier Ltd. and reproduced with permission). 
$\mathrm{Fe}^{3+}$ coordination polymer NDs (Fe-CPNDs) were synthesized through the self-assembling the multidental $\mathrm{Fe}^{3+}$-polyvinyl pyrrolidone (PVP) complexes and $\mathrm{Fe}^{3+}$-gallic acid (GA) complexes and used as nanotheranostics for MRI-guided PTT [107-109]. For instance, our group has developed a simple and scalable method for synthesizing the $\mathrm{pH}$-activated Fe coordination polymer NDs (Fe-CPNDs) by the coordination reactions among $\mathrm{Fe}^{3+}, \mathrm{GA}$, and PVP at ambient conditions (as shown in Figure 11) [107]. The Fe-CPNDs exhibit an ultrasmall hydrodynamic diameter $(5.3 \mathrm{~nm})$, nearly neutral Zeta potential $(-3.76 \mathrm{mV}), \mathrm{pH}$-activatable MRI imaging contrast $\left(\mathrm{r}_{1}=1.9 \mathrm{mM}^{-1} \cdot \mathrm{s}^{-1}\right.$ at $\left.\mathrm{pH} 5.0\right)$, and outstanding photothermal performance. The Fe-CPNDs were successfully used as $\mathrm{T}_{1}$-weighted MRCA to detect mouse-bearing tumors as small as $5 \mathrm{~mm}^{3}$ in volume, and as a PTT agent to completely suppress tumor growth by MRI-guided PTT, demonstrating that Fe-CPNDs constitute a new class of renal clearable theranostics. In addition, the Fe-CPND-enhanced MRI was successfully employed for noninvasively monitoring the kidney dysfunction by drug (daunomycin)-induced kidney injury, which further highlights the potential in clinical applications of the Fe-CPND [108].
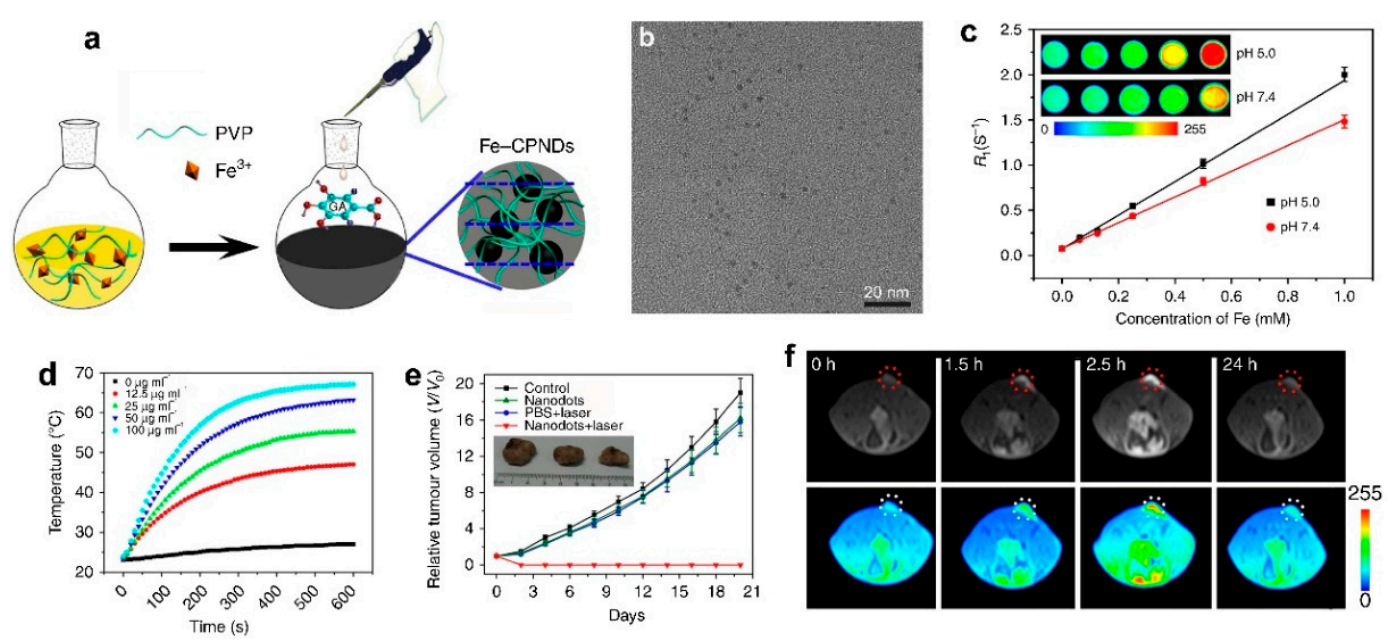

Figure 11. (a) Schematic representation of the synthesis of Fe-CPNDs. (b) TEM micrograph of Fe-CPNDs. (c) The effect of solution $\mathrm{pH}$ on the $\mathrm{R}_{1}$ relaxivity of Fe-CPNDs. (d) Temperature elevation of Fe-CPNDs solutions with various concentrations under $1.3 \mathrm{~W} \mathrm{~cm}^{-2} 808 \mathrm{~nm}$ NIR laser irradiation for $10 \mathrm{~min}$. (e) Tumor growth curves of different groups of mice after intravenous treatments. The inset shows the digital photographs of tumors collected from different groups of mice at day 20th post-administration. (f) In vivo MR images of the SW620 tumor-bearing nude mouse after intravenous injection of at a dose of $0.25 \mathrm{mg} \mathrm{Fe} \mathrm{kg}^{-1}$ (The tumor was marked by circle, which was about $5 \mathrm{~mm}^{3}$ in volume.) after the intravenous injection of Fe-CPNDs at different time intervals ( $0 \mathrm{~h}$ indicates pre-injection) (adapted from Liu et al. 2015 [107], Copyright 2015 Macmillan Publishers Ltd. and reproduced with permission).

Development of contrast agents for simultaneously $\mathrm{T}_{1}-/ \mathrm{T}_{2}$-weighted dual-mode MRI may circumvent the drawbacks of single imaging modalities. Iron-based NDs are also able to serve as $\mathrm{T}_{1}-/ \mathrm{T}_{2}$-weighted dual-mode MRCAs [110-113]. Uvdal and coauthors synthesized a series of water-dispersible PAA-coated $\mathrm{Fe}_{3} \mathrm{O}_{4}$ NDs via a modified one-step coprecipitation approach [110]. In particular, the $2.2 \mathrm{~nm}$ PAA coated $\mathrm{Fe}_{3} \mathrm{O}_{4} \mathrm{NDs}$ have relatively high relaxivities $\left(\mathrm{r}_{1}=6.15 \mathrm{mM}^{-1} \cdot \mathrm{s}^{-1}\right.$ and $r_{2}=28.62 \mathrm{mM}^{-1} \cdot \mathrm{s}^{-1}$ ) and low $\mathrm{r}_{2} / \mathrm{r}_{1}$ ratio (4.65). Using a mouse model, the in vivo experiments indicate that the $2.2 \mathrm{~nm}$ PAA-coated $\mathrm{Fe}_{3} \mathrm{O}_{4}$ NDs exhibit long-term circulation, low toxicity, and great contrast enhancement (brightened on the $\mathrm{T}_{1}$-weighted and darkened on the $\mathrm{T}_{2}$-weighted $\mathrm{MR}$ images), when the mice were then intravenously injected with PAA-coated $\mathrm{Fe}_{3} \mathrm{O}_{4}$ NDs with a dose of $0.0125 \mathrm{mmol} \mathrm{Fe} \mathrm{kg}{ }^{-1}$. The in vivo results demonstrate that the $2.2 \mathrm{~nm}$ PAA-coated $\mathrm{Fe}_{3} \mathrm{O}_{4} \mathrm{NDs}$ have great potential as $\mathrm{T}_{1}-/ \mathrm{T}_{2}$-weighted dual-mode MRCA for clinical applications including diagnosis of renal failure, myocardial infarction, atherosclerotic plaque, and tumor. Very recently, Shi and coauthors developed a strategy for preparing switchable $T_{1} / T_{2}$-weighted dual-mode MRCA by formation of 
cystamine dihydrochloride (Cys) cross-linked $\mathrm{Fe}_{3} \mathrm{O}_{4}$ NDs clusters [113]. The $\mathrm{Fe}_{3} \mathrm{O}_{4}$ NDs clusters, with a hydrodynamic size of $134.4 \mathrm{~nm}$, and can be dissociated to single $3.3 \mathrm{~nm} \mathrm{Fe} \mathrm{O}_{4}$ NDs under a reducing microenvironment (e.g., $10 \mathrm{mmol} \mathrm{L}^{-1}$ glutathione (GSH)) because of redox-responsiveness of the disulfide bond of Cys. The $\mathrm{Fe}_{3} \mathrm{O}_{4}$ NDs clusters exhibit a dominant $\mathrm{T}_{2}$-weighted MR effect with an $r_{2}$ of $26.4 \mathrm{mM}^{-1} \cdot \mathrm{s}^{-1}$, while $\mathrm{Fe}_{3} \mathrm{O}_{4}$ NDs have a strong $\mathrm{T}_{1}$-weighted MR effect with an $\mathrm{r}_{1}$ of $3.9 \mathrm{mM}^{-1} \cdot \mathrm{s}^{-1}$. Due to the reductive tumor microenvironment, the $\mathrm{Fe}_{3} \mathrm{O}_{4} \mathrm{NCs}$ can be utilized for dynamic precision imaging of a subcutaneous tumor model in vivo, and pass through the kidney filter, when the mice were then intravenously injected $\mathrm{Fe}_{3} \mathrm{O}_{4} \mathrm{NCs}$ with a dose of $2.5 \mathrm{mmol} \mathrm{Fe} \mathrm{kg}{ }^{-1}$.

\subsection{Other Paramagnetic Metal-Based Nanomaterials}

Due to their in vivo safety, $\mathrm{Mn}^{2+}$-based $\mathrm{T}_{1}$-weighted MRCAs have attracted increasing attention [114-134]. Although free $\mathrm{Mn}^{2+}$ has a higher $\mathrm{r}_{1}$ than those of Mn-based nanomaterials, $\mathrm{Mn}^{2+}$ exhibits low accumulation and poor performance for disease contrast because of its short blood retention time in vivo [114-119]. The increase of $\mathrm{Mn}^{2+}$ accumulation in a tumor can be achieved through the design of $\mathrm{pH} / \mathrm{GSH}$-activated $\mathrm{Mn}$-based nanomaterials because a tumor has weakly acidic microenvironment and high concentration of GSH, and nanomaterials can efficiently accumulate in a tumor by EPR effect [123-129]. Therefore, several tumor microenvironment activatable Mn-based nanotheranostic systems have been constructed for $\mathrm{T}_{1}$-weighted MRI-guided therapy. We have synthesized the polydopamine@ultrathin manganese dioxide/methylene blue nanoflowers (PDA@ut-MnO $2 / \mathrm{MB} \mathrm{NFs}$ ) for the $\mathrm{T}_{1}$-weighted MRI-guided PTT/photodynamic therapy (PDT) synergistic therapy of tumor (as shown in Figure 12) [125]. In the presence of $5 \mathrm{mmol} \cdot \mathrm{L}^{-1}$ GSH, the $\mathrm{r}_{1}$ of PDA@ut-MnO $2 / \mathrm{MB}$ NFs is significantly increased from 0.79 to $5.64 \mathrm{mM}^{-1} \cdot \mathrm{s}^{-1}$ since the ultrathin $\mathrm{MnO}_{2}$ nanosheets on PDA@ut- $\mathrm{MnO}_{2} / \mathrm{MB}$ NFs can be reduced into $\mathrm{Mn}^{2+}$ ions by GSH. Due to the performance in response to the tumor microenvironment, the PDA@ut- $\mathrm{MnO}_{2} / \mathrm{MB}$ NFs show an enhancement 3 times that of the $\mathrm{T}_{1}$-weighted MRI signal at the tumor site at $4 \mathrm{~h}$ post-injection. The $\mathrm{Mn}^{2+}$ can be diffused from the tumor to the circulatory system and excreted from the body through renal clearance. In addition, doping of $\mathrm{Mn}^{2+}$ into the matrix of other metallic NDs and/or formation of $\mathrm{Mn}^{2+}$-complexes/nanocomposites can also improve its $\mathrm{T}_{1}$-weighted MR contrast ability [115,130-134]. For example, Wang and coauthors developed a $\mathrm{Mn}^{2+}$-based MRCA (MNP-PEG-Mn) through chelation of $\mathrm{Mn}^{2+}$ with $5.6 \mathrm{~nm}$ water-soluble melanin NDs [134]. The $\mathrm{r}_{1}\left(20.56 \mathrm{mM}^{-1} \cdot \mathrm{s}^{-1}\right)$ of as-prepared MNP-PEG-Mn is much higher than that of Gadodiamide $\left(6.00 \mathrm{mM}^{-1} \cdot \mathrm{s}^{-1}\right)$. Using a 3T3 tumor-bearing mouse as model, in vivo MRI experiments demonstrated that MNP-PEG-Mn $\left(200 \mu \mathrm{L}\right.$ of $8 \mathrm{mg} \mathrm{mL}^{-1}$ MNP-PEG-Mn PBS solution) showed excellent tumor-targeting specificity, and could be efficiently excreted via renal and hepatobiliary pathways with negligible toxicity.

Because $\mathrm{Dy}^{3+}$ and $\mathrm{Ho}^{3+}$ ions exhibit relatively high magnetic moments among of lanthanide (III) $\left(\mathrm{Ln}^{3+}\right)$ ions, Dy and Ho NDs are believed as promising candidates for $\mathrm{T}_{2}$-weighted MRCAs with renal excretion [135-139]. As early as 2011, Lee and coauthors developed a facile one-pot method for synthesis of D-glucuronic acid-coated $\mathrm{Ln}_{2} \mathrm{O}_{3} \mathrm{NDs}$ ( $\mathrm{Ln}=\mathrm{Eu}, \mathrm{Gd}, \mathrm{Dy}, \mathrm{Ho}$, and $\mathrm{Er}$ ) [138]. They demonstrated that the D-glucuronic acid-coated $3.2 \mathrm{~nm} \mathrm{Dy}_{2} \mathrm{O}_{3} \mathrm{NDs}$ have high $\mathrm{r}_{2}\left(65.04 \mathrm{mM}^{-1} \cdot \mathrm{s}^{-1}\right)$ and very low $\mathrm{r}_{1}\left(0.008 \mathrm{mM}^{-1} \cdot \mathrm{s}^{-1}\right)$. After injection of the $\mathrm{Dy}_{2} \mathrm{O}_{3} \mathrm{NDs}$ at a dose of $0.05 \mathrm{mmol} \mathrm{Dy} \mathrm{kg}{ }^{-1}$ through tail vein of mouse, the clearly negative MR contrast enhancement in both liver and kidneys of mouse are observed in in vivo $\mathrm{T}_{2}$-weighted MRI. The $\mathrm{Dy}_{2} \mathrm{O}_{3} \mathrm{NDs}$ are also excreted from the body through the renal route, which is prerequisite for clinical applications as a MRCA. 

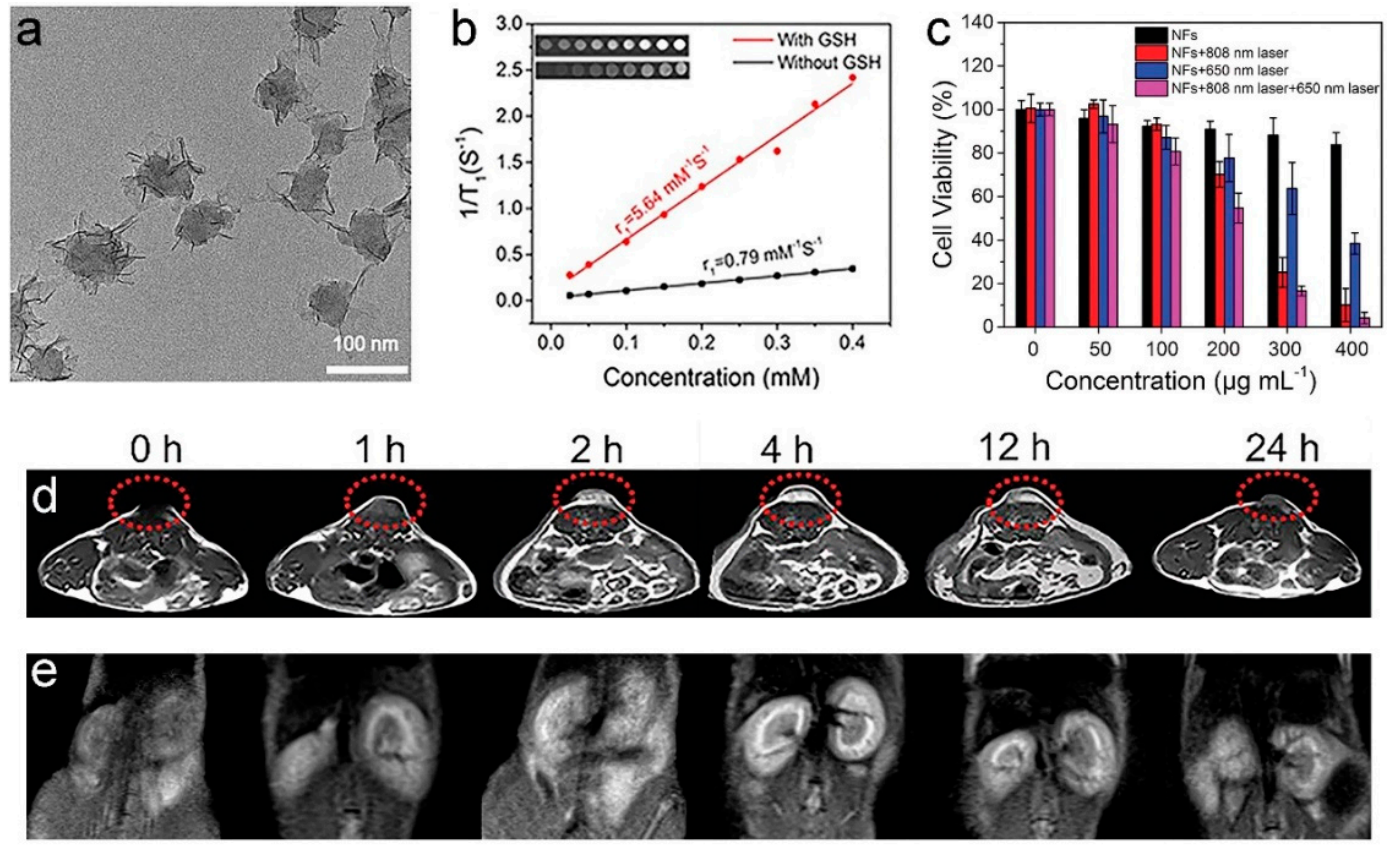

Figure 12. (a) TEM micrographs of PDA@ut-MnO $\mathrm{Mn}_{2} \mathrm{MB}$ NFs. (b) The $\mathrm{r}_{1}$ values of PDA@ut-MnO $\mathrm{Mn}_{2} / \mathrm{MB}$ NFs with and without $5 \mathrm{mmol} \mathrm{L}^{-1} \mathrm{GSH}$. (c) An assessment of PDT/PTT efficacy using PDA@ut-MnO $2 / \mathrm{MB}^{-}$ NFs via CCK-8 assays. In vivo MR images of HCT 116 tumor-bearing mouse (d) tumor and (e) kidneys different time points after the intravenous injection of PDA@ut- $\mathrm{MnO}_{2} / \mathrm{MB} \mathrm{NFs}(0,1,2,4,12$, and 24 h; $0 \mathrm{~h}$ means pre-injection) at a dose of $10 \mathrm{mg} \mathrm{Mn} \mathrm{kg}^{-1}$ (adapted from Sun et al. 2019 [125], Copyright 2019 The Royal Society of Chemistry and reproduced with permission).

\section{Dual Paramagnetic Metal Nanodots}

The MR contrast capabilities of nanomaterials can be further improved while two paramagnetic metallic ions are integrated into one nanoplatform [140-155]. For instance, Zhou and coauthors constructed a $4.95 \mathrm{~nm}$ triple-mode imaging platform by doping of $\mathrm{Mn}^{2+}$ and ${ }^{68}$ gallium (III) $\left({ }^{68} \mathrm{Ga}^{3+}\right)$ into the matrix of copper sulfide (CuS) NDs using BSA as the synthetic template [143]. Although the $\mathrm{Mn}^{2+} /{ }^{68} \mathrm{Ga}^{3+}$-CuS@BSA NDs have relatively low $\mathrm{r}_{1}\left(0.1119 \mathrm{mM}^{-1} \cdot \mathrm{s}^{-1}\right.$, the ratio of $\left.\mathrm{r}_{2} / \mathrm{r}_{1}=1.67\right)$, in vivo experimental results of SKOV-3 ovarian tumor-bearing mouse demonstrated that the as-prepared $\mathrm{Mn}^{2+} /{ }^{68} \mathrm{Ga}^{3+}$-CuS@BSA NDs (150 $\mu \mathrm{L}$ solution at 2 OD concentration of NDs) could be used as an excellent agent for $\mathrm{T}_{1}$-weihted MR/positron emission tomography (PET)/photoacoustic (PAT) triple-mode imaging-guided PTT of the tumor, and were efficiently cleared via the renal-urinary route. Very recently, our group constructed a multifunctional nanotheranostic (MnIOMCP) for active tumor-targeting $\mathrm{T}_{1}-\mathrm{T}_{2}$-weighted dual-mode MRI-guided biological-photothermal therapy (bio-PTT) through bioconjugation of the monocyclic peptides (MCP, the CXC chemokine receptor 4 (CXCR4) antagonist) with $3.8 \mathrm{~nm}$ manganese-doped iron oxide NDs (MnIO NDs) [146]. The MnIOMCP displays reasonable $\mathrm{T}_{1}-/ \mathrm{T}_{2}$-weighted MR contrast abilities $\left(\mathrm{r}_{1}=13.1 \mathrm{mM}^{-1} \cdot \mathrm{s}^{-1}, \mathrm{r}_{2}=46.6 \mathrm{mM}^{-1} \cdot \mathrm{s}^{-1}\right.$ and $\left.r_{2} / r_{1}=3.56\right)$, good photothermal conversion efficiency $(\eta=28.8 \%)$, strong tumor-targeting ability $\left(\sim 15.9 \% \mathrm{ID} \mathrm{g}^{-1}\right.$ at $1 \mathrm{~h}$ after intravenous injection with a dose of $\left.10 \mathrm{mg}[\mathrm{Mn}+\mathrm{Fe}] \mathrm{kg}^{-1}\right)$ and clear inhibition of CXCR4-positive tumor growth. In addition, the MnIOMCP at can be rapidly excreted from the body through renal clearance (about 75\% ID of MnIOMCP found in urine at $24 \mathrm{~h}$ post-injection), which illuminates a new pathway for the development of efficient nanotheranostics with high biosafety. In addition, the $r_{1}$ and/or $r_{2}$ values of $\mathrm{Ln}^{3+}$-based nanomaterials could be increased by mixing paramagnetic transition metal ions into them owing to unpaired 3d-electrons of transition metal ions [151-155]. Gao and coauthors reported a facile strategy to design and synthesis of zwitterionic dopamine sulfonate-coated $4.8 \mathrm{~nm}$ gadolinium-embedded iron oxide NDs (GdIO@ZDS), which showed a hydrodynamic diameter of about $5.2 \mathrm{~nm}$ in both PBS buffer and BSA solution [155]. The combination 
of the spincanting effects and the collection of $\mathrm{Gd}^{3+}$ within small-sized GdIO NDs led to a strongly enhanced $\mathrm{T}_{1}$-weighted MR contrast effect, which exhibited a high $\mathrm{r}_{1}$ of $7.85 \mathrm{mM}^{-1} \cdot \mathrm{s}^{-1}$ and a low $\mathrm{r}_{2} / \mathrm{r}_{1}$ ratio of 5.24. Using SKOV3-bearing mouse as a model, the in vivo experimental results demonstrated that the GdIO@ZDS with a dose of $2.0 \mathrm{mg}$ GdIO@ZDS kg-1 are suitable candidates as excellent $\mathrm{T}_{1}$-weighted MRCAs for tumor imaging and disease diagnosis because they have relatively long circulation half-life ( $\sim 50 \mathrm{~min})$, passive-tumor targeting capacity, and efficient renal clearance ability.

\section{Conclusions and Outlook}

In summary, we have illustrated the recent advances in the development of renal clearable MRCAs including $\mathrm{Gd}^{3+}$-based composites and MNDs. Compared to conventional small molecule $\mathrm{Gd}^{3+}$-complex contrast agents, the composites/MNDs have demonstrated improved MR signal intensity, targeting ability, and longer circulation time both in vitro and in small animal disease models, especially for cancer diagnosis. In particular, with the help of nanotechnology, the recent research developments have progressed towards construction of renal clearable MRCAs with multifunctionality, which enables us to integrate several functions at the same time, such as simultaneous disease targeting, multimodal imaging, and therapy. For instance, several unique characteristics of MNDs enable their use for selective cancer theragnostics, which include: (a) their size, which leads to preferential accumulation of MNDs in tumors though EPR effect, wide MRI time window by prolonging circulation time, and completely excreted from the body within a reasonable period of time (i.e., within a few of days) through renal clearance; (b) high surface-to-volume ratios, which result in strong enhancement of MR signal at ROI through increasing the interaction opportunities of ${ }^{1} \mathrm{H}$ with paramagnetic ions; and (c) large surface area, which exhibits the possibility to load different molecular therapeutics for MRI-guided therapy and/or functionalize with cancer-homing ligands for achieving positive-tumor targeting. The performance of MND-based MRCAs could be further improved through optimizing one or more of the above-mentioned characteristics of the MNDs. The renal clearable composite-/MND-based MRCAs have, indeed, bright prospects regarding their possibilities for biomedical applications, which have already been demonstrated in the scientific literature.

Unfortunately, very few MND-based MRCAs were approved for clinical application except SPIONs (Ferumoxides). On the other hand, the need for specific molecular information is greater than ever, since we are entering into the era of precision medicine. The noninvasive diagnostic or screening methods such as MRI can efficiently help patients to avoid ineffective and/or costly treatments because many of the newly developed powerful and expensive therapies are only effective in a subset of patients. This situation strongly requires the development of high-performance contrast agents to improve the accuracy of molecular imaging. The clinical translation of MND-based MRCAs research is generally impeded by the significant heterogeneity in the construction of these agents. Up to date, the MND-based MRCAs are still in the experimental stage. There are several technical challenges regarding the MND-based MRCAs for clinical trials that need to be clearly addressed before they are evaluated in humans. For example, the safety and efficacy of the MND-based MRCAs should be comprehensively evaluated. Ongoing research should focus on evaluating the biodistribution, pharmacokinetics, and ultimate fates in vivo, improving targeting specificity while minimizing toxicity, and demonstrating the translational potential with appropriate animal models. It is critical to develop cost-effective methods for the kilogram-scale production of MND-based MRCAs since the MRCAs are normally administered in gram quantities. This matter could be solved by systematic optimization of synthesis conditions of polyol methods and thermal decomposition methods. The leakage of $\mathrm{Gd}^{3+}$ should be minimized while $\mathrm{Gd}^{3+} \mathrm{NDs}$ were used as MRCAs. Future efforts should aim to synthesize chelating agents with a high $\mathrm{Gd}^{3+}$ binding constant, and/or develop coating materials with highly stable physicochemical properties and excellent biocompatibility. In addition, integration of two or more paramagnetic metallic elements into a single hybrid ND is beneficial to circumvent their individual drawbacks and potentially provide more comprehensive imaging information through $\mathrm{T}_{1}-/ \mathrm{T}_{2}$-weighted dual-mode MRI. The MNDs are providing revolutionary potential as new MRCAs, which could achieve various clinical applications 
through close cooperation among of multidisciplinary teams of chemists, materials scientists, biologists, pharmacists, physicians, and imaging experts, and have a strongly positive impact on human health.

Author Contributions: Writing — original draft preparation, X.L., Y.S., G.L. and Z.W.; writing-review and editing, X.L., L.M., G.L. and Z.W. All authors have read and agreed to the published version of the manuscript.

Funding: This research was funded by JILIN PROVINCIAL SCIENCE AND TECHNOLOGY DEPARTMENT and NATIONAL NATURAL SCIENCE FOUNDATION OF CHINA, grant numbers $20190701052 \mathrm{GH}$ and 21775145.

Acknowledgments: The authors would like to thank the Jilin Provincial Science and Technology Department, and National Natural Science Foundation of China for financial support.

Conflicts of Interest: The authors declare no conflict of interest.

\section{References}

1. Weissleder, R.; Mahmood, U. Molecular imaging. Radiology 2001, 219, 316-333. [CrossRef] [PubMed]

2. Smith, S.M.; Jenkinson, M.; Woolrich, M.W.; Beckmann, C.F.; Behrens, T.E.J.; Johansen-Berg, H.; Bannister, P.R.; De Luca, M.; Drobnjak, I.; Flitney, D.E.; et al. Advances in functional and structural MR image analysis and implementation as FSL. Neuroimage 2004, 23, S208-S219. [CrossRef] [PubMed]

3. Caravan, P.; Ellison, J.J.; McMurry, T.J.; Lauffer, R.B. Gadolinium(III) chelates as MRI contrast agents: Structure, dynamics, and applications. Chem. Rev. 1999, 99, 2293-2352. [CrossRef] [PubMed]

4. Werner, E.J.; Datta, A.; Jocher, C.J.; Raymond, K.N. High-relaxivity MRI contrast agents: Where coordination chemistry meets medical imaging. Angew. Chem. Int. Ed. 2008, 47, 8568-8580. [CrossRef]

5. Frey, N.A.; Peng, S.; Cheng, K.; Sun, S. Magnetic nanoparticles: Synthesis, functionalization, and applications in bioimaging and magnetic energy storage. Chem. Soc. Rev. 2009, 38, 2532-2542. [CrossRef]

6. Louie, A.Y. Multimodality imaging probes: Design and challenges. Chem. Rev. 2010, 110, 3146-3195. [CrossRef] [PubMed]

7. Law, G.-L.; Wong, W.-T. An introduction to molecular imaging. In The Chemistry of Molecular Imaging; John Wiley \& Sons, Inc.: Hoboken, NJ, USA, 2014; pp. 1-24.

8. Lohrke, J.; Frenzel, T.; Endrikat, J.; Alves, F.C.; Grist, T.M.; Law, M.; Lee, J.M.; Leiner, T.; Li, K.-C.; Nikolaou, K.; et al. 25 Years of contrast-enhanced MRI: Developments, current challenges and future perspectives. Adv. Ther. 2016, 33, 1-28. [CrossRef]

9. Wahsner, J.; Gale, E.M.; Rodriguez-Rodriguez, A.; Caravan, P. Chemistry of MRI contrast agents: Current challenges and new frontiers. Chem. Rev. 2019, 119, 957-1057. [CrossRef]

10. Brasch, R.C. Methods of contrast enhancement for NMR imaging and potential applications-A subject review. Radiology 1983, 147, 781-788. [CrossRef]

11. Gupta, A.K.; Gupta, M. Synthesis and surface engineering of iron oxide nanoparticles for biomedical applications. Biomaterials 2005, 26, 3995-4021. [CrossRef]

12. Xu, W.; Kattel, K.; Park, J.Y.; Chang, Y.; Kim, T.J.; Lee, G.H. Paramagnetic nanoparticle T-1 and T-2 MRI contrast agents. Phys. Chem. Chem. Phys. 2012, 14, 12687-12700. [CrossRef]

13. Knezevic, N.Z.; Gadjanski, I.; Durand, J.-O. Magnetic nanoarchitectures for cancer sensing, imaging and therapy. J. Mater. Chem. B 2019, 7, 9-23. [CrossRef]

14. Bao, Y.; Sherwood, J.A.; Sun, Z. Magnetic iron oxide nanoparticles as T-1 contrast agents for magnetic resonance imaging. J. Mater. Chem. C 2018, 6, 1280-1290. [CrossRef]

15. Zhou, Z.; Yang, L.; Gao, J.; Chen, X. Structure-relaxivity relationships of magnetic nanoparticles for magnetic resonance imaging. Adv. Mater. 2019, 31, 1804567. [CrossRef] [PubMed]

16. Han, X.; Xu, K.; Taratula, O.; Farsad, K. Applications of nanoparticles in biomedical imaging. Nanoscale 2019, 11, 799-819. [CrossRef]

17. Sun, C.; Lee, J.S.H.; Zhang, M. Magnetic nanoparticles in MR imaging and drug delivery. Adv. Drug Deliv. Rev. 2008, 60, 1252-1265. [CrossRef] [PubMed]

18. Longmire, M.; Choyke, P.L.; Kobayashi, H. Clearance properties of nano-sized particles and molecules as imaging agents: Considerations and caveats. Nanomedicine 2008, 3, 703-717. [CrossRef] [PubMed]

19. Qiao, R.; Yang, C.; Gao, M. Superparamagnetic iron oxide nanoparticles: From preparations to in vivo MRI applications. J. Mater. Chem. 2009, 19, 6274-6293. [CrossRef] 
20. Jain, T.K.; Reddy, M.K.; Morales, M.A.; Leslie-Pelecky, D.L.; Labhasetwar, V. Biodistribution, clearance, and biocompatibility of iron oxide magnetic nanoparticles in rats. Mol. Pharmaceut. 2008, 5, 316-327. [CrossRef]

21. Zhang, Y.-N.; Poon, W.; Tavares, A.J.; McGilvray, I.D.; Chan, W.C.W. Nanoparticle-liver interactions: Cellular uptake and hepatobiliary elimination. J. Control. Release 2016, 240, 332-348. [CrossRef]

22. Buchman, J.T.; Hudson-Smith, N.V.; Landy, K.M.; Haynes, C.L. Understanding nanoparticle toxicity mechanisms to inform redesign strategies to reduce environmental impact. Acc. Chem. Res. 2019, 52, 1632-1642. [CrossRef] [PubMed]

23. Choi, H.S.; Frangioni, J.V. Nanoparticles for biomedical imaging: Fundamentals of clinical translation. Mol. Imaging 2010, 9, 291-310. [CrossRef]

24. Runge, V.M. Critical questions regarding gadolinium deposition in the brain and body after injections of the gadolinium-based contrast agents, safety, and clinical recommendations in consideration of the EMA's pharmacovigilance and risk assessment committee recommendation for suspension of the marketing authorizations for 4 linear agents. Investig. Radiol. 2017, 52, 317-323.

25. Na, H.B.; Song, I.C.; Hyeon, T. Inorganic nanoparticles for MRI contrast agents. Adv. Mater. 2009, 21, 2133-2148. [CrossRef]

26. Lu, Z.R.; Parker, D.L.; Goodrich, K.C.; Wang, X.H.; Dalle, J.G.; Buswell, H.R. Extracellular biodegradable macromolecular gadolinium(III) complexes for MRI. Magn. Reson. Med. 2004, 51, 27-34. [CrossRef]

27. Villaraza, A.J.L.; Bumb, A.; Brechbiel, M.W. Macromolecules, dendrimers, and nanomaterials in magnetic resonance imaging: The interplay between size, function, and pharmacokinetics. Chem. Rev. 2010, 110, 2921-2959. [CrossRef] [PubMed]

28. Kelkar, S.S.; Reineke, T.M. Theranostics: Combining imaging and therapy. Bioconjug. Chem. 2011, 22, 1879-1903. [CrossRef]

29. Detappe, A.; Kunjachan, S.; Sancey, L.; Motto-Ros, V.; Biancur, D.; Drane, P.; Guieze, R.; Makrigiorgos, G.M.; Tillement, O.; Langer, R.; et al. Advanced multimodal nanoparticles delay tumor progression with clinical radiation therapy. J. Control. Release 2016, 238, 103-113. [CrossRef]

30. Pellico, J.; Ellis, C.M.; Davis, J.J. Nanoparticle-based paramagnetic contrast agents for magnetic resonance imaging. Contrast Media Mol. Imaging 2019, 1845637. [CrossRef]

31. Zhu, W.; Artemov, D. Biocompatible blood pool MRI contrast agents based on hyaluronan. Contrast Media Mol. Imaging 2011, 6, 61-68. [CrossRef]

32. Grogna, M.; Cloots, R.; Luxen, A.; Jerome, C.; Desreux, J.-F.; Detrembleur, C. Design and synthesis of novel DOTA $\left(\mathrm{Gd}^{3+}\right)$-polymer conjugates as potential MRI contrast agents. J. Mater. Chem. 2011, 21, 12917-12926. [CrossRef]

33. Schopf, E.; Sankaranarayanan, J.; Chan, M.; Mattrey, R.; Almutairi, A. An extracellular MRI polymeric contrast agent that degrades at physiological pH. Mol. Pharmaceut. 2012, 9, 1911-1918. [CrossRef] [PubMed]

34. Zhang, G.; Zhang, R.; Melancon, M.P.; Wong, K.; You, J.; Huang, Q.; Bankson, J.; Liang, D.; Li, C. The degradation and clearance of Poly(N-hydroxypropyl-L-glutamine)-DTPA-Gd as a blood pool MRI contrast agent. Biomaterials 2012, 33, 5376-5383. [CrossRef] [PubMed]

35. Xiao, Y.; Xue, R.; You, T.; Li, X.; Pei, F. A new biodegradable and biocompatible gadolinium (III)-polymer for liver magnetic resonance imaging contrast agent. Magn. Reson. Imaging 2015, 33, 822-828. [CrossRef] [PubMed]

36. Xiong, Z.; Wang, Y.; Zhu, J.; He, Y.; Qu, J.; Effenberg, C.; Xia, J.; Appelhans, D.; Shi, X. Gd-Chelated poly(propylene imine) dendrimers with densely organized maltose shells for enhanced MR imaging applications. Biomater. Sci. 2016, 4, 1622-1629. [CrossRef]

37. Moussaron, A.; Vibhute, S.; Bianchi, A.; Guenduez, S.; Kotb, S.; Sancey, L.; Motto-Ros, V.; Rizzitelli, S.; Cremillieux, Y.; Lux, F.; et al. Ultrasmall nanoplatforms as calcium-responsive contrast agents for magnetic resonance imaging. Small 2015, 11, 4900-4909. [CrossRef]

38. McLeod, S.M.; Robison, L.; Parigi, G.; Olszewski, A.; Drout, R.J.; Gong, X.; Islamoglu, T.; Luchinat, C.; Farha, O.K.; Meade, T.J. Maximizing magnetic resonance contrast in Gd(III) nanoconjugates: Investigation of proton relaxation in zirconium metal-organic frameworks. ACS Appl. Mater. Inter. 2020, 12, 41157-41166. [CrossRef] 
39. Shi, Y.; Pan, Y.; Zhong, J.; Yang, J.; Zheng, J.; Cheng, J.; Song, R.; Yi, C. Facile synthesis of gadolinium (III) chelates functionalized carbon quantum dots for fluorescence and magnetic resonance dual-modal bioimaging. Carbon 2015, 93, 742-750. [CrossRef]

40. Zhang, M.; Liu, X.; Huang, J.; Wang, L.; Shen, H.; Luo, Y.; Li, Z.; Zhang, H.; Deng, Z.; Zhang, Z. Ultrasmall graphene oxide based T-1 MRI contrast agent for in vitro and in vivo labeling of human mesenchymal stem cells. Nanomedicine 2018, 14, 2475-2483. [CrossRef]

41. Cao, T.; Zhou, X.; Zheng, Y.; Sun, Y.; Zhang, J.; Chen, W.; Zhang, J.; Zhou, Z.; Yang, S.; Zhang, Y.; et al. Chelator-free conjugation of Tc-99m and $\mathrm{Gd}^{3+}$ to pegylated nanographene oxide for dual-modality SPECT/MR imaging of lymph nodes. ACS Appl. Mater. Inter. 2017, 9, 42612-42621. [CrossRef]

42. Chen, H.; Wang, G.D.; Tang, W.; Todd, T.; Zhen, Z.; Tsang, C.; Hekmatyar, K.; Cowger, T.; Hubbard, R.B.; Zhang, W.; et al. Gd-encapsulated carbonaceous dots with efficient renal clearance for magnetic resonance imaging. Adv. Mater. 2014, 26, 6761-6766. [CrossRef]

43. Liang, G.; Ye, D.; Zhang, X.; Dong, F.; Chen, H.; Zhang, S.; Li, J.; Shen, X.; Kong, J. One-pot synthesis of $\mathrm{Gd}^{3+}$-functionalized gold nanoclusters for dual model (fluorescence/magnetic resonance) imaging. J. Mater. Chem. B 2013, 1, 3545-3552. [CrossRef] [PubMed]

44. Zhu, Q.; Pan, F.; Tian, Y.; Tang, W.; Yuan, Y.; Hu, A. Facile synthesis of Gd(III) metallosurfactant-functionalized carbon nanodots with high relaxivity as bimodal imaging probes. RSC Adv. 2016, 6, 29441-29447. [CrossRef]

45. Hu, D.-H.; Sheng, Z.-H.; Zhang, P.-F.; Yang, D.-Z.; Liu, S.-H.; Gong, P.; Gao, D.-Y.; Fang, S.-T.; Ma, Y.-F.; Cai, L.-T. Hybrid gold-gadolinium nanoclusters for tumor-targeted NIRF/CT/MRI triple-modal imaging in vivo. Nanoscale 2013, 5, 1624-1628. [CrossRef]

46. Zhang, J.; Hao, G.; Yao, C.; Hu, S.; Hu, C.; Zhang, B. Paramagnetic albumin decorated CuInS $2 / Z n S$ QDs for CD133(+) glioma bimodal MR/fluorescence targeted imaging. J. Mater. Chem. B 2016, 4, 4110-4118. [CrossRef]

47. Liang, G.; Xiao, L. Gd ${ }^{3+}$-Functionalized gold nanoclusters for fluorescence-magnetic resonance bimodal imaging. Biomater. Sci. 2017, 5, 2122-2130. [CrossRef]

48. Gao, A.; Kang, Y.-F.; Yin, X.-B. Red fluorescence-magnetic resonance dual modality imaging applications of gadolinium containing carbon quantum dots with excitation independent emission. New J. Chem. 2017, 41, 3422-3431. [CrossRef]

49. Truillet, C.; Bouziotis, P.; Tsoukalas, C.; Brugiere, J.; Martini, M.; Sancey, L.; Brichart, T.; Denat, F.; Boschetti, F.; Darbost, U.; et al. Ultrasmall particles for Gd-MRI and Ga-68-PET dual imaging. Contrast Media Mol. Imaging 2015, 10, 309-319. [CrossRef]

50. Luo, D.; Johnson, A.; Wang, X.; Li, H.; Erokwu, B.O.; Springer, S.; Lou, J.; Ramamurthy, G.; Flask, C.A.; Burda, C.; et al. Targeted radiosensitizers for MR-guided radiation therapy of prostate cancer. Nano Lett. 2020. [CrossRef]

51. Vivero-Escoto, J.L.; Taylor-Pashow, K.M.L.; Huxford, R.C.; Della Rocca, J.; Okoruwa, C.; An, H.; Lin, W.; Lin, W. Multifunctional mesoporous silica nanospheres with cleavable Gd(III) chelates as MRI contrast agents: Synthesis, characterization, target-specificity, and renal clearance. Small 2011, 7, 3519-3528. [CrossRef]

52. Ma, Y.; Mou, Q.; Sun, M.; Yu, C.; Li, J.; Huang, X.; Zhu, X.; Yan, D.; Shen, J. Cancer theranostic nanoparticles self-assembled from amphiphilic small molecules with equilibrium shift-induced renal clearance. Theranostics 2016, 6, 1703-1716. [CrossRef]

53. Baker, S.N.; Baker, G.A. Luminescent carbon nanodots: Emergent nanolights. Angew. Chem. Int. Ed. 2010, 49, 6726-6744. [CrossRef]

54. Lim, S.Y.; Shen, W.; Gao, Z. Carbon quantum dots and their applications. Chem. Soc. Rev. 2015, 44, 362-381. [CrossRef]

55. Garg, B.; Bisht, T. Carbon nanodots as peroxidase nanozymes for biosensing. Molecules 2016, $21,1653$. [CrossRef]

56. Pardo, J.; Peng, Z.; Leblanc, R.M. Cancer targeting and drug delivery using carbon-based quantum dots and nanotubes. Molecules 2018, 23, 378. [CrossRef]

57. Nekoueian, K.; Amiri, M.o.; Sillanpaa, M.; Marken, F.; Boukherroub, R.; Szunerits, S. Carbon-based quantum particles: An electroanalytical and biomedical perspective. Chem. Soc. Rev. 2019, 48, 4281-4316. [CrossRef]

58. Du, F.; Zhang, L.; Zhang, L.; Zhang, M.; Gong, A.; Tan, Y.; Miao, J.; Gong, Y.; Sun, M.; Ju, H.; et al. Engineered gadolinium-doped carbon dots for magnetic resonance imaging-guided radiotherapy of tumors. Biomaterials 2017, 121, 109-120. [CrossRef] 
59. Yu, C.; Xuan, T.; Chen, Y.; Zhao, Z.; Liu, X.; Lian, G.; Li, H. Gadolinium-doped carbon dots with high quantum yield as an effective fluorescence and magnetic resonance bimodal imaging probe. J. Alloys Compd. 2016, 688, 611-619. [CrossRef]

60. Zhao, Y.; Hao, X.; Lu, W.; Wang, R.; Shan, X.; Chen, Q.; Sun, G.; Liu, J. Facile preparation of double rare earth-doped carbon dots for MRI/CT/FI multimodal imaging. ACS Appl. Nano Mater. 2018, 1, 2544-2551. [CrossRef]

61. Gong, N.; Wang, H.; Li, S.; Deng, Y.; Chen, X.; Ye, L.; Gu, W. Microwave-assisted polyol synthesis of gadolinium-doped green luminescent carbon dots as a bimodal nanoprobe. Langmuir 2014, 30, 10933-10939. [CrossRef]

62. Engstrom, M.; Klasson, A.; Pedersen, H.; Vahlberg, C.; Kall, P.-O.; Uvdal, K. High proton relaxivity for gadolinium oxide nanoparticles. MAGMA 2006, 19, 180-186. [CrossRef] [PubMed]

63. Park, J.Y.; Baek, M.J.; Choi, E.S.; Woo, S.; Kim, J.H.; Kim, T.J.; Jung, J.C.; Chae, K.S.; Chang, Y.; Lee, G.H. Paramagnetic ultrasmall gadolinium oxide nanoparticles as advanced T-1 MR1 contrast agent: Account for large longitudinal relaxivity, optimal particle diameter, and in vivo T-1 MR images. ACS Nano 2009, 3, 3663-3669. [CrossRef] [PubMed]

64. Xu, W.; Park, J.Y.; Kattel, K.; Bony, B.A.; Heo, W.C.; Jin, S.; Park, J.W.; Chang, Y.; Do, J.Y.; Chae, K.S.; et al. A T-1, T-2 magnetic resonance imaging (MRI)-fluorescent imaging (FI) by using ultrasmall mixed gadolinium-europium oxide nanoparticles. New J. Chem. 2012, 36, 2361-2367. [CrossRef]

65. Kim, C.R.; Baeck, J.S.; Chang, Y.; Bae, J.E.; Chae, K.S.; Lee, G.H. Ligand-size dependent water proton relaxivities in ultrasmall gadolinium oxide nanoparticles and in vivo T-1 MR images in a $1.5 \mathrm{~T}$ MR field. Phy. Chem. Chem. Phy. 2014, 16, 19866-19873. [CrossRef] [PubMed]

66. Ahmad, M.W.; Kim, C.R.; Baeck, J.S.; Chang, Y.; Kim, T.J.; Bae, J.E.; Chaed, K.S.; Lee, G.H. Bovine serum albumin (BSA) and cleaved-BSA conjugated ultrasmall $\mathrm{Gd}_{2} \mathrm{O}_{3}$ nanoparticles: Synthesis, characterization, and application to MRI contrast agents. Colloid. Surf. A 2014, 450, 67-75. [CrossRef]

67. Miao, X.; Ho, S.L.; Tegafaw, T.; Cha, H.; Chang, Y.; Oh, I.T.; Yaseen, A.M.; Marasini, S.; Ghazanfari, A.; Yue, H.; et al. Stable and non-toxic ultrasmall gadolinium oxide nanoparticle colloids (coating material = polyacrylic acid) as high-performance T-1 magnetic resonance imaging contrast agents. RSC Adv. 2018, 8, 3189-3197. [CrossRef]

68. Ho, S.L.; Cha, H.; Oh, I.T.; Jung, K.-H.; Kim, M.H.; Lee, Y.J.; Miao, X.; Tegafaw, T.; Ahmad, M.Y.; Chae, K.S.; et al. Magnetic resonance imaging, gadolinium neutron capture therapy, and tumor cell detection using ultrasmall $\mathrm{Gd}_{2} \mathrm{O}_{3}$ nanoparticles coated with polyacrylic acid-rhodamine $\mathrm{B}$ as a multifunctional tumor theragnostic agent. RSC Adv. 2018, 8, 12653-12665. [CrossRef]

69. Miao, X.; Xu, W.; Cha, H.; Chang, Y.; Oh, I.T.; Chae, K.S.; Tegafaw, T.; Ho, S.L.; Kim, S.J.; Lee, G.H. Ultrasmall $\mathrm{Gd}_{2} \mathrm{O}_{3}$ nanoparticles surface-coated by polyacrylic acid (PAA) and their PAA-size dependent relaxometric properties. Appl. Surf. Sci. 2019, 477, 111-115. [CrossRef]

70. Yue, H.; Marasini, S.; Ahmad, M.Y.; Ho, S.L.; Cha, H.; Liu, S.; Jang, Y.J.; Tegafaw, T.; Ghazanfari, A.; Miao, X.; et al. Carbon-coated ultrasmall gadolinium oxide $\left(\mathrm{Gd}_{2} \mathrm{O}_{3} @ \mathrm{C}\right)$ nanoparticles: Application to magnetic resonance imaging and fluorescence properties. Colloid. Surf. A 2020, 586, 124261. [CrossRef]

71. Ahren, M.; Selegard, L.; Klasson, A.; Soderlind, F.; Abrikossova, N.; Skoglund, C.; Bengtsson, T.; Engstrom, M.; Kall, P.-O.; Uvdal, K. Synthesis and characterization of PEGylated $\mathrm{Gd}_{2} \mathrm{O}_{3}$ nanoparticles for MRI contrast enhancement. Langmuir 2010, 26, 5753-5762. [CrossRef]

72. Le Duc, G.; Miladi, I.; Alric, C.; Mowat, P.; Braeuer-Krisch, E.; Bouchet, A.; Khalil, E.; Billotey, C.; Janier, M.; Lux, F.; et al. Toward an image-guided microbeam radiation therapy using gadolinium-based nanoparticles. ACS Nano 2011, 5, 9566-9574. [CrossRef] [PubMed]

73. Lux, F.; Mignot, A.; Mowat, P.; Louis, C.; Dufort, S.; Bernhard, C.; Denat, F.; Boschetti, F.; Brunet, C.; Antoine, R.; et al. Ultrasmall rigid particles as multimodal probes for medical applications. Angew. Chem. Int. Ed. 2011, 50, 12299-12303. [CrossRef] [PubMed]

74. Faucher, L.; Tremblay, M.; Lagueux, J.; Gossuin, Y.; Fortin, M.-A. Rapid synthesis of PEGylated ultrasmall gadolinium oxide nanoparticles for cell labeling and tracking with MRI. ACS Appl. Mater. Inter. 2012, 4, 4506-4515. [CrossRef] [PubMed]

75. Viger, M.L.; Sankaranarayanan, J.; de Gracia Lux, C.; Chan, M.; Almutairi, A. Collective activation of MRI agents via encapsulation and disease-triggered release. J. Am. Chem. Soc. 2013, 135, 7847-7850. [CrossRef] [PubMed] 
76. Li, Y.; Chen, T.; Tan, W.; Talham, D.R. Size-dependent MRI relaxivity and dual imaging with $\mathrm{Eu}_{0.2} \mathrm{Gd}_{0.8} \mathrm{PO}_{4}$ center dot $\mathrm{H}_{2} \mathrm{O}$ nanoparticles. Langmuir 2014, 30, 5873-5879. [CrossRef]

77. Fang, J.; Chandrasekharan, P.; Liu, X.-L.; Yang, Y.; Lv, Y.-B.; Yang, C.-T.; Ding, J. Manipulating the surface coating of ultra-small $\mathrm{Gd}_{2} \mathrm{O}_{3}$ nanoparticles for improved T-1-weighted MR imaging. Biomaterials 2014, 35, 1636-1642. [CrossRef]

78. Vahdatkhah, P.; Hosseini, H.R.M.; Khodaei, A.; Montazerabadi, A.R.; Irajirad, R.; Oghabian, M.A.; Delavari, H.H. Rapid microwave-assisted synthesis of PVP-coated ultrasmall gadolinium oxide nanoparticles for magnetic resonance imaging. Chem. Phys. 2015, 453, 35-41. [CrossRef]

79. Dufort, S.; Le Duc, G.; Salome, M.; Bentivegna, V.; Sancey, L.; Brauer-Krisch, E.; Requardt, H.; Lux, F.; Coll, J.-L.; Perriat, P.; et al. The high radiosensitizing efficiency of a trace of gadolinium-based nanoparticles in tumors. Sci. Rep. 2016, 6, 29678. [CrossRef]

80. Cheng, Y.; Lu, T.; Wang, Y.; Song, Y.; Wang, S.; Lu, Q.; Yang, L.; Tan, F.; Li, J.; Li, N. Glutathione-mediated clearable nanoparticles based on ultrasmall $\mathrm{Gd}_{2} \mathrm{O}_{3}$ for MSOT/CT/MR imaging guided photothermal/radio combination cancer therapy. Mol. Pharmaceut. 2019, 16, 3489-3501. [CrossRef]

81. Bony, B.A.; Miller, H.A.; Tarudji, A.W.; Gee, C.C.; Sarella, A.; Nichols, M.G.; Kievit, F.M. Ultrasmall mixed Eu-Gd oxide nanoparticles for multimodal fluorescence and magnetic resonance imaging of passive accumulation and retention in TBI. ACS Omega 2020, 5, 16220-16227. [CrossRef]

82. Johnson, N.J.J.; Oakden, W.; Stanisz, G.J.; Prosser, R.S.; van Veggel, F.C.J.M. Size-tunable, ultrasmall NaGdF 4 nanoparticles: Insights into their T-1 MRI contrast enhancement. Chem. Mater. 2011, 23, 3714-3722. [CrossRef]

83. Liu, Q.; Feng, W.; Yang, T.; Yi, T.; Li, F. Upconversion luminescence imaging of cells and small animals. Nat. Protoc. 2013, 8, 2033-2044. [CrossRef]

84. Xing, H.; Zhang, S.; Bu, W.; Zheng, X.; Wang, L.; Xiao, Q.; Ni, D.; Zhang, J.; Zhou, L.; Peng, W.; et al. Ultrasmall $\mathrm{NaGdF}_{4}$ nanodots for efficient $\mathrm{MR}$ angiography and atherosclerotic plaque imaging. Adv. Mater. 2014, 26, 3867-3872. [CrossRef] [PubMed]

85. Ni, D.; Shen, Z.; Zhang, J.; Zhang, C.; Wu, R.; Liu, J.; Yi, M.; Wang, J.; Yao, Z.; Bu, W.; et al. Integrating anatomic and functional dual mode magnetic resonance imaging: Design and applicability of a bifunctional contrast agent. ACS Nano 2016, 10, 3783-3790. [CrossRef] [PubMed]

86. Liu, F.; He, X.; Zhang, J.; Zhang, H.; Wang, Z. Employing tryptone as a general phase transfer agent to produce renal clearable nanodots for bioimaging. Small 2015, 11, 3676-3685. [CrossRef]

87. Yan, Y.; Ding, L.; Liu, L.; Abualrejal, M.M.A.; Chen, H.; Wang, Z. Renal-clearable hyaluronic acid functionalized $\mathrm{NaGdF}_{4}$ nanodots with enhanced tumor accumulation. RSC Adv. 2020, 10, 13872-13878. [CrossRef]

88. Chen, H.; Li, X.; Liu, F.; Zhang, H.; Wang, Z. Renal clearable peptide functionalized $\mathrm{NaGdF}_{4}$ nanodots for high-efficiency tracking orthotopic colorectal tumor in mouse. Mol. Pharmaceut. 2017, 14, 3134-3141. [CrossRef]

89. Chen, Y.; Fu, Y.; Li, X.; Chen, H.; Wang, Z.; Zhang, H. Peptide-functionalized NaGdF 4 nanoparticles for tumor-targeted magnetic resonance imaging and effective therapy. RSC Adv. 2019, 9, 17093-17100. [CrossRef]

90. Sun, W.; Luo, L.; Feng, Y.; Qiu, Y.; Shi, C.; Meng, S.; Chen, X.; Chen, H. Gadolinium-rose bengal coordination polymer nanodots for MR-/Fluorescence-image-guided radiation and photodynamic therapy. Adv. Mater. 2020, 32, 2000377. [CrossRef]

91. Tassa, C.; Shaw, S.Y.; Weissleder, R. Dextran-coated iron oxide nanoparticles: A versatile platform for targeted molecular imaging, molecular diagnostics, and therapy. Acc. Chem. Res. 2011, 44, 842-852. [CrossRef]

92. Wong, X.Y.; Sena-Torralba, A.; Alvarez-Diduk, R.; Muthoosamy, K.; Merkoci, A. Nanomaterials for nanotheranostics: Tuning their properties according to disease needs. ACS Nano 2020, 14, 2585-2627. [CrossRef] [PubMed]

93. Farzin, A.; Etesami, S.A.; Quint, J.; Memic, A.; Tamayol, A. Magnetic nanoparticles in cancer therapy and diagnosis. Adv. Healthc. Mater. 2020, 9, 1901058. [CrossRef] [PubMed]

94. Dardzinski, B.J.; Schmithorst, V.J.; Holland, S.K.; Boivin, G.P.; Imagawa, T.; Watanabe, S.; Lewis, J.M.; Hirsch, R. MR imaging of murine arthritis using ultrasmall superparamagnetic iron oxide particles. Magn. Reson. Imaging 2001, 19, 1209-1216. [CrossRef]

95. Wang, Y.; Xu, C.; Chang, Y.; Zhao, L.; Zhang, K.; Zhao, Y.; Gao, F.; Gao, X. Ultrasmall superparamagnetic iron oxide nanoparticle for T-2-weighted magnetic resonance imaging. ACS Appl. Mater. Interfaces 2017, 9, 28959-28966. [CrossRef] 
96. Kim, B.H.; Lee, N.; Kim, H.; An, K.; Park, Y.I.; Choi, Y.; Shin, K.; Lee, Y.; Kwon, S.G.; Na, H.B.; et al. Large-scale synthesis of uniform and extremely small-sized iron oxide nanoparticles for high-resolution T-1 magnetic resonance imaging contrast agents. J. Am. Chem. Soc. 2011, 133, 12624-12631. [CrossRef]

97. Li, P.; Chevallier, P.; Ramrup, P.; Biswas, D.; Vuckovich, D.; Fortin, M.-A.; Oh, J.K. Mussel-inspired multidentate block copolymer to stabilize ultrasmall superparamagnetic $\mathrm{Fe}_{3} \mathrm{O}_{4}$ for magnetic resonance imaging contrast enhancement and excellent colloidal stability. Chem. Mater. 2015, 27, 7100-7109. [CrossRef]

98. Yoon, J.; Cho, S.H.; Seong, H. Multifunctional ultrasmall superparamagnetic iron oxide nanoparticles as a theranostic agent. Colloid. Surf. A 2017, 520, 892-902. [CrossRef]

99. Tromsdorf, U.I.; Bruns, O.T.; Salmen, S.C.; Beisiegel, U.; Weller, H. A highly effective, nontoxic T-1 MR contrast agent based on ultrasmall pegylated iron oxide nanoparticles. Nano Lett. 2009, 9, 4434-4440. [CrossRef]

100. Vangijzegem, T.; Stanicki, D.; Panepinto, A.; Socoliuc, V.; Vekas, L.; Muller, R.N.; Laurent, S. Influence of experimental parameters of a continuous flow process on the properties of very small iron oxide nanoparticles (VSION) designed for $\mathrm{T}_{1}$-weighted magnetic resonance imaging (MRI). Nanomaterials 2020, 10, 757. [CrossRef]

101. Iqbal, M.Z.; Ma, X.; Chen, T.; Zhang, L.e.; Ren, W.; Xiang, L.; Wu, A. Silica-coated super-paramagnetic iron oxide nanoparticles (SPIONPs): A new type contrast agent of T-1 magnetic resonance imaging (MRI). J. Mater. Chem. B 2015, 3, 5172-5181. [CrossRef]

102. Ma, D.; Chen, J.; Luo, Y.; Wang, H.; Shi, X. Zwitterion-coated ultrasmall iron oxide nanoparticles for enhanced T-1-weighted magnetic resonance imaging applications. J. Mater. Chem. B 2017, 5, 7267-7273. [CrossRef]

103. Wei, H.; Bruns, O.T.; Kaul, M.G.; Hansen, E.C.; Barch, M.; Wisniowska, A.; Chen, O.; Chen, Y.; Li, N.; Okada, S.; et al. Exceedingly small iron oxide nanoparticles as positive MRI contrast agents. Proc. Natl. Acad. Sci. USA 2017, 114, 2325-2330. [CrossRef] [PubMed]

104. Yang, W.; Xiang, C.; Xu, Y.; Chen, S.; Zeng, W.; Liu, K.; Jin, X.; Zhou, X.; Zhang, B. Albumin-constrained large-scale synthesis of renal clearable ferrous sulfide quantum dots for T-1-Weighted MR imaging and phototheranostics of tumors. Biomaterials 2020, 255, 120186. [CrossRef] [PubMed]

105. Wei, R.; Cai, Z.; Ren, B.W.; Li, A.; Lin, H.; Zhang, K.; Chen, H.; Shan, H.; Ai, H.; Gao, J. Biodegradable and renal-clearable hollow porous iron oxide nanoboxes for in vivo imaging. Chem. Mater. 2018, 30, 7950-7961. [CrossRef]

106. Luo, Y.; Yang, J.; Yan, Y.; Li, J.; Shen, M.; Zhang, G.; Mignani, S.; Shi, X. RGD- functionalized ultrasmall iron oxide nanoparticles for targeted T-1-weighted MR imaging of gliomas. Nanoscale 2015, 7, 14538-14546. [CrossRef] [PubMed]

107. Liu, F.; He, X.; Chen, H.; Zhang, J.; Zhang, H.; Wang, Z. Gram-scale synthesis of coordination polymer nanodots with renal clearance properties for cancer theranostic applications. Nat. Commun. 2015, 6, 8003. [CrossRef]

108. Li, X.; Chen, H.; Liu, F.; Chen, Y.; Zhang, H.; Wang, Z. Accurate monitoring of renal injury state through in vivo magnetic resonance imaging with ferric coordination polymer nanodots. ACS Omega 2018, 3, 4918-4923. [CrossRef]

109. Chen, L.; Chen, J.; Qiu, S.; Wen, L.; Wu, Y.; Hou, Y.; Wang, Y.; Zeng, J.; Feng, Y.; Li, Z.; et al. Biodegradable nanoagents with short biological half-life for SPECT/PAI/MRI multimodality imaging and PTT therapy of tumors. Small 2018, 14, 1702700. [CrossRef]

110. Wang, G.; Zhang, X.; Skallberg, A.; Liu, Y.; Hu, Z.; Mei, X.; Uvdal, K. One-step synthesis of water-dispersible ultra-small $\mathrm{Fe}_{3} \mathrm{O}_{4}$ nanoparticles as contrast agents for T-1 and T-2 magnetic resonance imaging. Nanoscale 2014, 6, 2953-2963. [CrossRef]

111. Zhou, H.; Tang, J.; Li, J.; Li, W.; Liu, Y.; Chen, C. In vivo aggregation-induced transition between T-1 and T-2 relaxations of magnetic ultra-small iron oxide nanoparticles in tumor microenvironment. Nanoscale 2017, 9, 3040-3050. [CrossRef]

112. Li, X.; Lu, S.; Xiong, Z.; Hu, Y.; Ma, D.; Lou, W.; Peng, C.; Shen, M.; Shi, X. Light-addressable nanoclusters of ultrasmall iron oxide nanoparticles for enhanced and dynamic magnetic resonance imaging of arthritis. Adv. Sci. 2019, 6, 1901800. [CrossRef]

113. Ma, D.; Shi, M.; Li, X.; Zhang, J.; Fan, Y.; Sun, K.; Jiang, T.; Peng, C.; Shi, X. Redox-sensitive clustered ultrasmall iron oxide nanoparticles for switchable T-2/T-1-Weighted magnetic resonance imaging applications. Bioconjugate Chem. 2020, 31, 352-359. [CrossRef] [PubMed]

114. Zhen, Z.; Xie, J. Development of manganese-based nanoparticles as contrast probes for magnetic resonance imaging. Theranostics 2012, 2, 45-54. [CrossRef] [PubMed] 
115. Botta, M.; Carniato, F.; Esteban-Gomez, D.; Platas-Iglesias, C.; Tei, L. Mn(II) compounds as an alternative to Gd-based MRI probes. Future Med. Chem. 2019, 11, 1461-1483. [CrossRef] [PubMed]

116. Na, H.B.; Lee, J.H.; An, K.; Park, Y.I.; Park, M.; Lee, I.S.; Nam, D.-H.; Kim, S.T.; Kim, S.-H.; Kim, S.-W.; et al. Development of a T-1 contrast agent for magnetic resonance imaging using MnO nanoparticles. Angew. Chem. Int. Ed. 2007, 46, 5397-5401. [CrossRef]

117. Shin, J.; Anisur, R.M.; Ko, M.K.; Im, G.H.; Lee, J.H.; Lee, I.S. Hollow manganese oxide nanoparticles as multifunctional agents for magnetic resonance imaging and drug delivery. Angew. Chem. Int. Ed. 2009, 48, 321-324. [CrossRef] [PubMed]

118. Letourneau, M.; Tremblay, M.; Faucher, L.; Rojas, D.; Chevallier, P.; Gossuin, Y.; Lagueux, J.; Fortin, M.-A. MnO-labeled cells: Positive contrast enhancement in MRI. J. Phys. Chem. B 2012, 116, 13228-13238. [CrossRef]

119. Lu, Y.; Zhang, L.; Li, J.; Su, Y.-D.; Liu, Y.; Xu, Y.-J.; Dong, L.; Gao, H.-L.; Lin, J.; Man, N.; et al. MnO nanocrystals: A platform for integration of MRI and genuine autophagy induction for chemotherapy. Adv. Funct. Mater. 2013, 23, 1534-1546. [CrossRef]

120. Chevallier, P.; Walter, A.; Garofalo, A.; Veksler, I.; Lagueux, J.; Begin-Colin, S.; Felder-Flesch, D.; Fortin, M.A. Tailored biological retention and efficient clearance of pegylated ultra-small MnO nanoparticles as positive MRI contrast agents for molecular imaging. J. Mater. Chem. B 2014, 2, 1779-1790. [CrossRef]

121. McDonagh, B.H.; Singh, G.; Hak, S.; Bandyopadhyay, S.; Augestad, I.L.; Peddis, D.; Sandvig, I.; Sandvig, A.; Glomm, W.R. L-DOPA-coated manganese oxide nanoparticles as dual MRI contrast agents and drug-delivery vehicles. Small 2016, 12, 301-306. [CrossRef]

122. Zhan, Y.; Zhan, W.; Li, H.; Xu, X.; Cao, X.; Zhu, S.; Liang, J.; Chen, X. In Vivo Dual-modality fluorescence and magnetic resonance imaging-guided lymph node mapping with good biocompatibility manganese oxide nanoparticles. Molecules 2017, 22, 2208. [CrossRef]

123. Cai, X.; Gao, W.; Ma, M.; Wu, M.; Zhang, L.; Zheng, Y.; Chen, H.; Shi, J. A prussian blue-based core-shell hollow-structured mesoporous nanoparticle as a smart theranostic agent with ultrahigh ph-responsive longitudinal relaxivity. Adv. Mater. 2015, 27, 6382-6389. [CrossRef]

124. Wang, D.; Lin, H.; Zhang, G.; Si, Y.; Yang, H.; Bai, G.; Yang, C.; Zhong, K.; Cai, D.; Wu, Z.; et al. Effective $\mathrm{pH}$-activated theranostic platform for synchronous magnetic resonance imaging diagnosis and chemotherapy. ACS Appl. Mater. Interfaces 2018, 10, 31114-31123. [CrossRef] [PubMed]

125. Sun, Y.; Chen, H.; Liu, G.; Ma, L.; Wang, Z. The controllable growth of ultrathin $\mathrm{MnO}_{2}$ on polydopamine nanospheres as a single nanoplatform for the MRI-guided synergistic therapy of tumors. J. Mater. Chem. B 2019, 7, 7152-7161. [CrossRef] [PubMed]

126. Gong, F.; Cheng, L.; Yang, N.; Betzer, O.; Feng, L.; Zhou, Q.; Li, Y.; Chen, R.; Popovtzer, R.; Liu, Z. Ultrasmall oxygen-deficient bimetallic oxide $\mathrm{MnWO}_{\mathrm{X}}$ nanoparticles for depletion of endogenous GSH and enhanced sonodynamic cancer therapy. Adv. Mater. 2019, 31, 1900730. [CrossRef]

127. Zheng, S.; Zhang, M.; Bai, H.; He, M.; Dong, L.; Cai, L.; Zhao, M.; Wang, Q.; Xu, K.; Li, J. Preparation of AS1411 aptamer modified Mn-MoS 2 QDs for targeted MR imaging and fluorescence labelling of renal cell carcinoma. Int. J. Nanomed. 2019, 14, 9513-9524. [CrossRef]

128. Li, J.; Wu, C.; Hou, P.; Zhang, M.; Xu, K. One-pot preparation of hydrophilic manganese oxide nanoparticles as T-1 nano-contrast agent for molecular magnetic resonance imaging of renal carcinoma in vitro and in vivo. Biosens. Bioelectron. 2018, 102, 1-8. [CrossRef] [PubMed]

129. Meng, J.; Zhao, Y.; Li, Z.; Wang, L.; Tian, Y. Phase transfer preparation of ultrasmall MnS nanocrystals with a high performance MRI contrast agent. RSC Adv. 2016, 6, 6878-6887. [CrossRef]

130. Chen, A.; Sun, J.; Liu, S.; Li, L.; Peng, X.; Ma, L.; Zhang, R. The effect of metal ions on endogenous melanin nanoparticles used as magnetic resonance imaging contrast agents. Biomater. Sci. 2020, 8, 379-390. [CrossRef]

131. Sun, J.; Xu, W.; Li, L.; Fan, B.; Peng, X.; Qu, B.; Wang, L.; Li, T.; Li, S.; Zhang, R. Ultrasmall endogenous biopolymer nanoparticles for magnetic resonance/photoacoustic dual-modal imaging-guided photothermal therapy. Nanoscale 2018, 10, 10584-10595. [CrossRef]

132. Jin, M.; Li, W.; Spillane, D.E.M.; Geraldes, C.F.G.C.; Williams, G.R.; Bligh, S.W.A. Hydroxy double salts intercalated with $\mathrm{Mn}(\mathrm{II})$ complexes as potential contrast agents. Solid State Sci. 2016, 53, 9-16. [CrossRef]

133. Wu, Y.; Xu, L.; Qian, J.; Shi, L.; Su, Y.; Wang, Y.; Li, D.; Zhu, X. Methotrexate-Mn²+ based nanoscale coordination polymers as a theranostic nanoplatform for MRI guided chemotherapy. Biomater. Sci. 2020, 8 , 712-719. [CrossRef] [PubMed] 
134. Xu, W.; Sun, J.; Li, L.; Peng, X.; Zhang, R.; Wang, B. Melanin-manganese nanoparticles with ultrahigh efficient clearance in vivo for tumor-targeting T-1 magnetic resonance imaging contrast agent. Biomater. Sci. 2018, 6, 207-215. [CrossRef] [PubMed]

135. Bottrill, M.; Nicholas, L.K.; Long, N.J. Lanthanides in magnetic resonance imaging. Chem. Soc. Rev. 2006, 35, 557-571. [CrossRef] [PubMed]

136. Kattel, K.; Park, J.Y.; Xu, W.; Kim, H.G.; Lee, E.J.; Bony, B.A.; Heo, W.C.; Jin, S.; Baeck, J.S.; Chang, Y.; et al. Paramagnetic dysprosium oxide nanoparticles and dysprosium hydroxide nanorods as T-2 MRI contrast agents. Biomaterials 2012, 33, 3254-3261. [CrossRef]

137. Yue,H.; Park, J.Y.; Chang, Y.; Lee, G.H. Ultrasmall europium, gadolinium, and dysprosium oxide nanoparticles: Polyol synthesis, properties, and biomedical imaging applications. Mini Rev. Med. Chem. 2020. [CrossRef]

138. Kattel, K.; Park, J.Y.; Xu, W.; Kim, H.G.; Lee, E.J.; Bony, B.A.; Heo, W.C.; Lee, J.J.; Jin, S.; Baeck, J.S.; et al. A facile synthesis, in vitro and in vivo MR studies of D-glucuronic acid-coated ultrasmall $\mathrm{Ln}\left({ }_{2}\right) \mathrm{O}\left({ }_{3}\right)(\mathrm{Ln}=\mathrm{Eu}$, Gd, Dy, Ho, and Er) nanoparticles as a new potential MRI contrast agent. ACS Appl. Mater. Interfaces 2011, 3, 3325-3334. [CrossRef]

139. Das, G.K.; Zhang, Y.; D’Silva, L.; Padmanabhan, P.; Heng, B.C.; Loo, J.S.C.; Selvan, S.T.; Bhakoo, K.K.; Tan, T.T.Y. Single-phase $\mathrm{Dy}_{2} \mathrm{O}_{3}: \mathrm{Tb}^{3+}$ nanocrystals as dual-modal contrast agent for high field magnetic resonance and optical imaging. Chem. Mater. 2011, 23, 2439-2446. [CrossRef]

140. Hu, F.; Zhao, Y.S. Inorganic nanoparticle-based T-1 and T-1/T-2 magnetic resonance contrast probes. Nanoscale 2012, 4, 6235-6243. [CrossRef]

141. Shokrollahi, H. Contrast agents for MRI. Mat. Sci. Eng. C-Mater. 2013, 33, 4485-4497. [CrossRef]

142. Zeng, L.; Ren, W.; Zheng, J.; Cui, P.; Wu, A. Ultrasmall water-soluble metal-iron oxide nanoparticles as T-1-weighted contrast agents for magnetic resonance imaging. Phys. Chem. Chem. Phys. 2012, 14, 2631-2636. [CrossRef] [PubMed]

143. Zhou, B.; Zhao, J.; Qiao, Y.; Wei, Q.; He, J.; Li, W.; Zhong, D.; Ma, F.; Li, Y.; Zhou, M. Simultaneous multimodal imaging and photothermal therapy via renal-clearable manganese-doped copper sulfide nanodots. Appl. Mater. Today 2018, 13, 285-297. [CrossRef]

144. Li, Z.; Wang, S.X.; Sun, Q.; Zhao, H.L.; Lei, H.; Lan, M.B.; Cheng, Z.X.; Wang, X.L.; Dou, S.X.; Lu, G.Q. Ultrasmall manganese ferrite nanoparticles as positive contrast agent for magnetic resonance imaging. Adv. Healthc. Mater. 2013, 2, 958-964. [CrossRef] [PubMed]

145. Zhang, H.; Li, L.; Liu, X.L.; Jiao, J.; Ng, C.-T.; Yi, J.B.; Luo, Y.E.; Bay, B.-H.; Zhao, L.Y.; Peng, M.L.; et al. Ultrasmall ferrite nanoparticles synthesized via dynamic simultaneous thermal decomposition for high-performance and multifunctional T-1 magnetic resonance imaging contrast agent. ACS Nano 2017, 11, 3614-3631. [CrossRef] [PubMed]

146. Fu, Y.; Li, X.; Chen, H.; Wang, Z.; Yang, W.; Zhang, H. CXC chemokine receptor 4 antagonist functionalized renal clearable manganese-doped iron oxide nanoparticles for active-tumor-targeting magnetic resonance imaging-guided bio-photothermal therapy. ACS Appl. Bio Mater. 2019, 2, 3613-3621. [CrossRef]

147. Xiao, S.; Yu, X.; Zhang, L.; Zhang, Y.; Fan, W.; Sun, T.; Zhou, C.; Liu, Y.; Liu, Y.; Gong, M.; et al. Synthesis of PEG-Coated, Ultrasmall, manganese-doped iron oxide nanoparticles with high relaxivity for T-1/T-2 dual-contrast magnetic resonance imaging. Int. J. Nanomed. 2019, 14, 8499-8507. [CrossRef] [PubMed]

148. Miao, Y.; Xie, Q.; Zhang, H.; Cai, J.; Liu, X.; Jiao, J.; Hu, S.; Ghosal, A.; Yang, Y.; Fan, H. Composition-tunable ultrasmall manganese ferrite nanoparticles: Insights into their in vivo T-1 contrast efficacy. Theranostics 2019, 9, 1764-1776. [CrossRef]

149. Tan, L.; Wan, J.; Guo, W.; Ou, C.; Liu, T.; Fu, C.; Zhang, Q.; Ren, X.; Liang, X.-J.; Ren, J.; et al. Renal-clearable quaternary chalcogenide nanocrystal for photoacoustic/magnetic resonance imaging guided tumor photothermal therapy. Biomaterials 2018, 159, 108-118. [CrossRef]

150. Tegafaw, T.; Xu, W.; Ahmad, M.W.; Baeck, J.S.; Chang, Y.; Bae, J.E.; Chae, K.S.; Kim, T.J.; Lee, G.H. Dual-mode T-1 and T-2 magnetic resonance imaging contrast agent based on ultrasmall mixed gadolinium-dysprosium oxide nanoparticles: Synthesis, characterization, and in vivo application. Nanotechnology 2015, 26, 365102. [CrossRef]

151. Jin, X.; Fang, F.; Liu, J.; Jiang, C.; Han, X.; Song, Z.; Chen, J.; Sun, G.; Lei, H.; Lu, L. An ultrasmall and metabolizable PEGylated $\mathrm{NaGdF}_{4}$ :Dy nanoprobe for high-performance T-1/T-2-weighted MR and CT multimodal imaging. Nanoscale 2015, 7, 15680-15688. [CrossRef] 
152. Bony, B.A.; Baeck, J.S.; Chang, Y.; Bae, J.E.; Chae, K.S.; Lee, G.H. Water-soluble D-glucuronic acid coated ultrasmall mixed $\mathrm{Ln} / \mathrm{Mn}$ ( $\mathrm{Ln}=\mathrm{Gd}$ and Dy) oxide nanoparticles and their application to magnetic resonance imaging. Biomater. Sci. 2014, 2, 1287-1295. [CrossRef] [PubMed]

153. Wang, X.; Hu, H.; Zhang, H.; Li, C.; An, B.; Dai, J. Single ultrasmall Mn²+-doped $\mathrm{NaNdF}_{4}$ nanocrystals as multimodal nanoprobes for magnetic resonance and second near-infrared fluorescence imaging. Nano Res. 2018, 11, 1069-1081. [CrossRef]

154. Yang, M.; Liu, Y.; Wang, M.; Yang, C.; Sun, S.; Zhang, Q.; Guo, J.; Wang, X.; Sun, G.; Peng, Y. Biomineralized Gd/Dy composite nanoparticles for enhanced tumor photoablation with precise T-1/T-2-MR/CT/thermal imaging guidance. Chem. Eng. J. 2020, 391, 123562. [CrossRef]

155. Zhou, Z.; Wang, L.; Chi, X.; Bao, J.; Yang, L.; Zhao, W.; Chen, Z.; Wang, X.; Chen, X.; Gao, J. Engineered iron-oxide-based nanoparticles as enhanced T-1 contrast agents for efficient tumor imaging. ACS Nano 2013, 7, 3287-3296. [CrossRef]

Publisher's Note: MDPI stays neutral with regard to jurisdictional claims in published maps and institutional affiliations.

(C) 2020 by the authors. Licensee MDPI, Basel, Switzerland. This article is an open access article distributed under the terms and conditions of the Creative Commons Attribution (CC BY) license (http://creativecommons.org/licenses/by/4.0/). 